\title{
Conscientiousness, Education, and Longevity of High-Ability Individuals
}

\author{
Working paper \\ Peter A. Savelyev* \\ Department of Economics \\ Vanderbilt University
}

December 30, 2011

${ }^{*}$ A version of this paper was presented to the Health Economics Workshop, the University of Chicago, in September 2010, the Labor Group, department of Economics, the University of Chicago, in July and October 2010; the Upjohn Institute for Employment Research seminar, in January 2011; the department of Finance of David Eccles School of Business research seminar, University of Utah, January 2011; and department of Economics at Vanderbilt University seminar in February 2011. I thank participants of these meetings for useful suggestions and stimulating discussions. I am grateful to Gary Becker, Gabriella Conti, Miriam Gensowski, Jim Heckman, Tim Kautz, Willard Manning, David Meltzer, Rémi Piatek, and Ben Williams for helpful comments. This paper was supported by the Merck Quantitative Science Graduate Fellowship in Health Economics. The views expressed in this paper are those of the author and may not coincide with those of the funder. Supplementary materials may be retrieved from http://home.uchicago.edu/ psavel/papers/JMP/!TermanLongevityPaper-appx.pdf. 


\begin{abstract}
In this paper, I investigate whether higher education causally affects longevity. I also investigate the role of personality in producing longevity taking into account its potential interaction with education. The causal status of higher education in affecting health and longevity is unclear in the literature, largely because unknown confounding factors, reverse causality, and difficulty in finding instrumental variables that are both valid and sufficiently strong to reliably estimate the causal effect of higher education on longevity. I examine whether there are confounding factors among early cognitive and noncognitive traits. I estimate the causal effect by controlling for latent confounding psychology factors and for the reverse causality.

I represent noncognitive traits by traits that are close to the established Big Five taxonomy of personality, and find a trait of Conscientiousness that has strong effects on both education and longevity. I estimate a model that uses Conscientiousness and education as arguments of a production function for longevity. The model accounts for the endogeneity of education, measurement error in the proxies for Conscientiousness, age-dependence in the effect of education on longevity, and the interaction between education and Conscientiousness in producing longevity. I estimate the model using the 1922-1991 Terman life cycle data of children with high ability, a prospective study with unique life cycle information including detailed background characteristics, early health measures, personality ratings, IQ, and mortality observations.

My results show that both Conscientiousness and education increase longevity for males, but that the effect of Conscientiousness on longevity is only strong at low levels of education, and the effect of education on longevity is especially strong at low levels of Conscientiousness. In addition, I show that a failure to account for Conscientiousness leads to a generally upward bias in the estimate of the effect of education on longevity. The bias from omitting Conscientiousness is comparable to the bias from omitting all other control variables in the model. For females, I find that the effects of education and Conscientiousness are not precisely determined. I argue that this lack of strong effects for females born around 1910 might not be generalizable to contemporary female population.
\end{abstract}

Key words: longevity, higher education, cognitive traits, noncognitive traits, personality, Conscientiousness, factor analysis, measurement error, interaction, Terman life cycle data of children with high ability, gender difference

JEL codes: C33, C38, C41, D91, I12, J24 


\section{Introduction}

In his influential model of the demand for health, Grossman (1972) uses education as an argument in the health production function. However, the causal effect of education on health and longevity is only beginning to be understood. Although there is no doubt that education is strongly correlated with health and longevity, the causal effects of education have only been firmly established for a limited range of education levels (compulsory education), for particular age intervals, and for specific measures of health and health behaviors (e.g., Adams (2002); Arendt (2005, 2008); Auld and Sidhu (2005); Conti et al. (2010a,c); Cutler and Lleras-Muney (2010); Grossman (2000, 2006); Grossman and Kaestner (1997); LlerasMuney (2005); Silles (2009); Spasojevic (2003)).

Despite the strong correlation between education and health, it is difficult to determine whether education has a causal effect on longevity because of two econometric problems: reverse causality (expected longevity may affect education), and confounding variables (unobserved factors such as noncognitive traits may affect both education and longevity) (Becker, 2007; Conti et al., 2010a,c; Farrell and Fuchs, 1982; Fuchs, 1982; Grossman, 2000). ${ }^{1}$ Establishing causality is especially difficult for higher education because it is hard to find valid and sufficiently strong instrumental variables that make it possible to reliably estimate the causal effect of schooling above typical compulsory levels. This paper aims to establish a causal link between higher education and longevity by accounting for cognitive and noncognitive traits as potential confounding factors and by controlling for reverse causality.

The search for confounding factors among noncognitive traits is motivated both by the emerging literature in cognitive and noncognitive economics and by the literature in personality psychology. Research in cognitive and noncognitive economics has shown strong effects of noncognitive traits on essential life outcomes including health and education (Borghans et al., 2008; Conti et al., 2010a,c; Heckman et al., 2011, 2006; Kaestner, 2009). Research in personality psychology has shown that noncognitive traits, especially a personality trait

\footnotetext{
${ }^{1}$ I address the reverse causality problem later in Section 4.6.1
} 
of Conscientiousness, are correlated with both longevity and education (Friedman, 2008; Friedman et al., 1994, 1995, 1993; Hampson and Friedman, 2008; Martin et al., 2007, 2002).

To study the effect of cognitive and noncognitive traits on education and longevity, I use the Terman life cycle data of children with high ability (Terman, 1986), the longest prospective longitudinal dataset ever collected (Friedman et al., 1995). The dataset covers the years 1922-1991 and contains about 4,500 variables. ${ }^{2}$ The sample consists of 1,583 schoolchildren from California. On average, the subjects are born in 1910, and with the exceptions described in Section 2, have IQs above 140. Although the respondents are rather homogenous in IQ, they differ substantially in all other traits. ${ }^{3}$ The Terman dataset includes a rich variety of information on each subject, including the respondent's early health conditions, IQ, personality measures, parental education and occupation, parental origin, history of private tutoring, World War II experience, and dates of birth and death. By 1991, about $62 \%$ of the males and $52 \%$ of the females had died. Additionally, comprehensive education data for each subject were gathered both prospectively and retrospectively multiple times over the life cycle. The availability of detailed background information and of multiple proxies for latent noncognitive traits facilitates establishing a causal effect of education on longevity by making it possible to condition on essential observable and latent variables.

The Terman dataset is one of the most widely known datasets among psychologists, but it is relatively unknown to economists. ${ }^{4}$ However, the recent spate of major developments in the new field of cognitive and noncognitive economics, which bridges economics and personality psychology (Almlund et al., 2010; Borghans et al., 2008; Cunha and Heckman, 2007; Heckman et al., 2006), has elicited a renewed interest in the dataset due to its unique combination of

\footnotetext{
${ }^{2}$ Years 1922-91 are covered prospectively. Retrospectively, the survey covers even longer period through questions asked in 1922 about conditions at birth (about 1910), conditions after birth, and family background.

${ }^{3}$ In the literature it is suggested that except for the trait of Openness, the Big Five psychological traits are generally uncorrelated with IQ (e.g., Ackerman and Heggestad (1997); Borghans et al. (2011); DeYoung et al. (2005)).

${ }^{4}$ In the 1970s, economists published several papers based on the Terman data. The papers are concerned with marriage and divorce decisions, consumption and retirement, fertility and children's schooling, and home investments in children (Becker et al., 1977; Hamermesh, 1984; Leibowitz, 1974; Michael, 1976; Tomes, 1981).
} 
detailed life-cycle measurements.

Using data from the Terman study, I identify the causal effect of post-high school education on longevity by accounting for potentially confounding latent noncognitive traits. (see also Borghans et al. (2008); Carneiro et al. (2003); Heckman et al. (2011, 2006, 2001, 2003); Heckman and Vytlacil (2007)). Similarly to Heckman et al. (2006), I assume that conditional on detailed background characteristics, all dependences between longevity and education choices come from cognitive and noncognitive traits. I represent noncognitive traits by traits that are theoretically and statistically similar to the established Big Five personality traits, and find that a trait of Conscientiousness plays a major role in determining both longevity and education. ${ }^{5}$ In contrast, I find that the remaining near-Big Five personality traits - Openness, Extraversion, Agreeableness, and Neuroticism - do not contribute to explanatory power while consuming many degrees of freedom. ${ }^{6}$ I estimate a system of two models with latent Conscientiousness: a discrete time proportional odds model of hazard of death with time-dependent effects, and a generalized ordered logit model of educational investment choice. Both models account for latent personality. I account for the endogeneity of education, the measurement error in proxies of traits, and the age-dependence in the effect of education on longevity (see Figure 1).

For males, both Conscientiousness and education increase longevity. In addition, Conscientiousness increases education, and so its omission leads to a bias. Moreover, I find a previously unknown interaction between Conscientiousness and education in producing longevity. The effect of Conscientiousness on longevity decreases with educational attainment, while

\footnotetext{
${ }^{5}$ The Big Five Conscientiousness is defined as "individual differences in the propensity to follow socially prescribed norms for impulse control, to be task- and goal- directed, to be planful, to delay gratification, and to follow norms and rules" (John and Srivastava, 1999). Conscientiousness as measured in this paper was empirically shown to be related to the Big Five Conscientiousness with correlation coefficient 0.55 and $p$-value below 0.001 (Martin and Friedman, 2000).

${ }^{6}$ Conscientiousness, Openness, and Extraversion are childhood traits measured in 1922. Since measures for the remaining two Big Five traits, Agreeableness and Neuroticism, are not available for 1922, I use those from 1940. These results are in line with the results obtained by psychologists based on the Terman data who find that among a number of childhood traits, early Conscientiousness is the only strong and robust predictor of longevity (Martin et al., 2007). In addition, the authors find that adult Neuroticism, Agreeableness, and Extraversion are not predictive of longevity.
} 
the effect of education on longevity decreases with Conscientiousness. I conjecture that this interaction occurs because education and Conscientiousness affect longevity through multiple common mediators, such as smoking and drinking habits, diet, mental health, physical exercise, and patient adherence to medical protocols. Once high Conscientiousness has resulted in beneficial levels of these mediators, little additional improvement can be produced by additional education (and vice versa).

For females I find greater longevity than for males, but the effects of education and Conscientiousness on longevity are generally not statistically significant. ${ }^{7}$ However, given that many developments have occurred in women's lifestyles and in the job and marriage markets for females (Chiappori et al., 2009), these results may be specific to women born at the beginning of the $20^{\text {th }}$ century and may not apply to later generations.

The greater longevity of females compared to males is well established in the literature. Women are more biologically robust, less exposed to risky and unhealthy behaviors, and use more preventative care (see, for example, Read and Gorman (2010)). Healthier lifestyles of females may explain the lack of strong effects of education and Conscientiousness. Since women already practice healthy behaviors, education and Conscientiousness cannot cause much further improvement. ${ }^{8}$

Although the results of this paper are obtained for individuals with extraordinarily high IQs, they might also apply to a much broader population. Indeed, health is produced primarily by leading a healthy lifestyle (Bogg and Roberts, 2004; Hampson and Friedman, 2008; Phelps, 2010), and healthy behaviors do not intrinsically require extraordinary levels of cognitive ability. ${ }^{9}$ The results of this paper may apply to individuals with high, but

\footnotetext{
${ }^{7}$ There is a positive effect of Conscientiousness on longevity for females with incomplete college education.

${ }^{8}$ Statistically insignificant effects of Conscientiousness for females of the Terman sample were also found by Friedman et al. (1993). Authors conjecture that the effects of Conscientiousness on health and longevity could be smaller for female Terman subjects because women have historically played a more restricted role in society than men, and thus had less opportunities to practice unhealthy behaviors.

${ }^{9}$ In their meta-analysis of Conscientiousness-related traits and the leading behavioral contributors to mortality in the United States, Bogg and Roberts (2004) provide evidence that Conscientiousness is negatively related to health-related behaviors such as tobacco use, diet and activity patterns, excessive alcohol use, violence, risky sexual behavior, risky driving, suicide, and drug use.
} 
not necessarily extraordinarily high, cognition, such as those successful in high school and college. Because such individuals tend to be the most productive part of the work force, the results of this paper may have strong implications for important aggregates such as the demand for education, the demand for health, the labor supply, private investments, and government revenues.

My main contributions to health economics include the establishment of a strong causal effect of higher education on longevity for high-ability males, the establishment of Conscientiousness as a confounding factor in the effect of education on longevity, and the discovery of a strong education-Conscientiousness interaction that makes the causal effect of education on longevity dependent on the level of Conscientiousness. I also suggest that Conscientiousness is a potential policy variable that should be considered in health economics research.

The establishment of the causal effect of higher education on longevity supplements findings about the causal effects of compulsory education on health and longevity based on using compulsory schooling laws as instrumental variables (Adams, 2002; Arendt, 2005, 2008; Lleras-Muney, 2005; Mazumder, 2008; Silles, 2009; Spasojevic, 2003). I also confirm and supplement Grossman's finding that higher education benefits the health of men with above average cognitive ability (Grossman, 1975), and I caution against extrapolation of the findings by Auld and Sidhu (2005) outside the range of particular health outcomes and relatively young ages specific to their paper. ${ }^{10}$

The establishment of Conscientiousness as a confounding factor in the effect of education on longevity supplements findings by Fuchs (1982) and Cutler and Lleras-Muney (2010). Fuchs (1982) studied the role of time preference as a potential confounding factor but did not find any strong effect, possibly due to measurement error. In a recent paper, Cutler and Lleras-Muney (2010) dismiss the role of personality as a confounding factor, reporting that their personality factors do not account for any of the education gradient. However,

\footnotetext{
${ }^{10}$ Auld and Sidhu (2005) find that schooling has a large effect "only for individuals who obtain low levels of schooling, particularly low-ability individuals" and "years of schooling beyond high school contribute very little to health." Authors obtain their results for two binary health limitations and a general health index measured at ages below 43 .
} 
the authors do not directly account for the trait of Conscientiousness, and acknowledge that their use of noisy proxies may dismiss potentially important theories. In contrast to Fuchs (1982) and Cutler and Lleras-Muney (2010), I explicitly account for measurement error. I find that the bias from omitting Conscientiousness is comparable to the bias from omitting all other controls, which include parental education, occupation, origin, and many other essential variables (see Table 2).

Finally, I contribute to the bodies of literature on health psychology, personality psychology, and the Terman data. Although recent analyses based on the Terman data have shown that Conscientiousness is associated with both longevity and education (Friedman, 2000, 2008; Friedman et al., 1994, 1995, 1993; Hampson and Friedman, 2008; Lippa et al., 2000; Martin et al., 2007, 2002), I use a more elaborate methodology and discover a strong interaction between Conscientiousness and education in producing longevity. ${ }^{11}$

\section{Terman Data Description}

The Terman Life Cycle Study of Children with High Ability started in 1921 with follow-ups every 5-10 years through 1991. The sample consists of 856 males and 672 females. Selection of the gifted children was based on teacher's nomination followed by an IQ test. ${ }^{12}$ Subjects were selected for having an IQ above $140,{ }^{13}$ which corresponds to the $99.6^{\text {th }}$ percentile of the intelligence distribution.

Terman's selection procedure led to a sample of mostly middle-class, white schoolchil-

\footnotetext{
${ }^{11}$ I also perform a new exploratory factor analysis based on the year 1922 personality ratings (see Web Appendix A available from http://home.uchicago.edu/ psavel/papers/JMP/!TermanLongevityPaperappx.pdf), and find that one additional childhood personality trait can be identified (Openness), which has been overlooked in exploratory factor analyses by other authors.

${ }^{12}$ Teachers nominated from one to five children, usually four, from classes of 30-50 pupils. Teachers were asked to base nominations on intelligence, quickness of grasp, originality, ability to reason clearly about new and difficult problems, breadth and accuracy of information, command of language, common sense, and independence of judgment. They were also asked to take age into account and nominate younger children other things being equal. Terman et al. (1925)

${ }^{13}$ To be more precise, 180 children had IQs in the range of $135-139$, and an additional 7 had IQs in the range 126-135. Information about the type of IQ test is included later in this section.
} 
dren. ${ }^{14}$ The subjects were born, on average, in 1910 with standard deviation 2 . The study has an attrition rate below $10 \%$, which is exceptionally low for a 70-year-long prospective study. Moreover, those lost are known not to differ systematically in terms of education, income, and demographic factors (Sears, 1984). There is also no evidence that members of the attrited group differ significantly from others on measures of personality (Friedman et al., 1993).

About 4,500 measurements collected in the period 1922-1991 describe detailed family backgrounds, parental investments, personality traits, health statuses, and economic outcomes, among others (Burks et al., 1930; Terman et al., 1925; Terman and Oden, 1959; Terman et al., 1947; Terman and Sears, 2002a,b; Terman et al., 2002).

The key variables used in this paper include five binary education variables, the IQ variable, and personality measures. Education refers to the highest level of education achieved in life, up to 1986. The most prevalent education attainment for both genders is a bachelor's degree. Doctorates are almost as common as bachelor's degrees among males, but very uncommon for females. The second largest category among females is a master's degree, which is almost as frequent as "some college." The smallest education category for both genders is high school graduate. ${ }^{15}$ One important benefit of the longitudinal nature of the Terman study, with education data collected multiple times prospectively and retrospectively, is that measurement error in education is negligible after correcting the education variable based on all available information. ${ }^{16}$

The average IQ is about 149 for both males and females. Children already in high school, about $30 \%$ of the sample, took an intelligence test called the Terman Group Test (TGT) instead of the Stanford Binet Test. ${ }^{17}$

\footnotetext{
${ }^{14}$ Terman et al. (1925) refers to the economic status of a majority of families as "fairly comfortable," and indicates that only a few families were "truly in poverty."

${ }^{15}$ There are also several high school dropouts, whom I drop from the sample as outliers (see below in this section).

${ }^{16}$ See the Web Appendix by Gensowski, Heckman, and Savelyev (2011) for a description of corrections made to the education variable. I use the same corrections for this paper.

${ }^{17}$ The Stanford-Binet test is the 1916 Stanford revison of the Binet-Simon Intelligence Test. In longevity and schooling models, I use what is called "the best measure of IQ" constructed by psychologists from all
} 
In order to measure personality, I calculate the average of parents' and teachers' ratings of personality traits in 1922, when children were, on average, 12 years of age. ${ }^{18}$ This averaging procedure allows me to increase the sample of non-missing personality measures, and to account for additional information. ${ }^{19}$ Psychological literature on Terman data personality traits (Friedman, 2000, 2008; Friedman et al., 1994, 1995, 1993; Hampson and Friedman, 2008; Martin et al., 2007, 2002) is also based on averages of teachers' and parents' ratings, as explicitly stated in Martin et al. (2002). For Conscientiousness and Openness, the averages of measures are generally below zero for people with lower education and above zero for those with higher education (measures are standardized so that the sample mean is zero). See Table 1 for more information on these key variables.

Background variables in this paper are used for the purposes of achieving causal inference, not for investigating their effects. The background variables can be grouped into seven categories: parental education and occupation, parental origin, early health, private tutoring, other family background, World War II experience, ${ }^{20}$ and cohort. On average, compared to less educated subjects, highly educated subjects have higher fathers' and mothers' education, fathers' professional occupation, and World War II participation. They also have lower incidences of their fathers holding a semiprofessional or clerical occupation, either parent being from outside of the US, having a deceased father, or having divorced parents. See Table 2 for more information on the background variables.

I restrict the data based on a number of criteria determined prior to estimation. I

available tests in order to correct for various measurement issues (Terman and Sears, 2002a). As a precaution, I check if the effect of IQ is different for the TGT takers, but observe no difference.

${ }^{18}$ If both teachers' and parents' ratings are present, I average them. If one of them is absent, I use the only one that is available.

${ }^{19}$ It would be best to derive a common factor through a hierarchical (higher order) factor model (see, for instance Bollen (1989)), but this option is not available, because at least three sources of ratings (e.g., parents, teachers, and peers) are needed for the identification of such a model, while the Terman study only contains two. Thus, I perform a standard factor analysis on averaged items rather than the hierarchical factor analysis on items based on responses of different raters.

${ }^{20}$ World War II experience, which includes war and combat participation, was to a large extent determined by draft lottery and orders of the miliary, which can be considered as exogenous variation. Clearly, some of endogenous variation can not be ruled out (e.g., volunteering). I made a robustness check and found that results are robust to the exclusion World War II variables from the model. 
exclude: (1) 155 people who were not born in the period $1904-1915 ;^{21}$ (2) 41 people who never participated, were lost, or dropped out before $1940 ;^{22}$ (3) 47 people who are missing both parents' and teachers' personality trait ratings; ${ }^{23}$ (4) 15 high school dropouts; ${ }^{24}$ (5) two men who died in service during World War II; ${ }^{25}$ (6) six people with serious diseases in their early life, such as chorea or Hodgkin's disease ${ }^{26}(7)$ seven people who have missing education level information; (8) 24 people who died before age $31 ;{ }^{27}$ and (9) 51 people for whom childhood Conscientiousness measures are missing. The final estimation sample contains 1,180 people; 661 males and 519 females. Criteria (1-3) are identical or similar to those used by psychologists (Martin et al., 2007).

\section{$3 \quad$ Modeling Noncognitive Traits}

An emerging cognitive and noncognitive literature (e.g., Borghans et al. (2008); Conti et al. (2009); Cunha and Heckman (2009); Cunha et al. (2006); Heckman et al. (2011)) demonstrates the vital importance of noncognitive traits. Perhaps the most established contemporary taxonomy of noncognitive traits is the Big Five taxonomy (John and Srivastava, 1999) developed by personality psychologists. In this paper, I use methods and concepts from personality psychology and use five factors that are strongly related to the Big Five personality traits both theoretically and empirically and have the same names as the Big Five factors. ${ }^{28}$

\footnotetext{
${ }^{21}$ This restriction makes the cohorts more comparable by excluding long tails of the year of birth distribution.

${ }^{22}$ From now on I report observations dropped from the sub-sample that remained after all previous filtering, so that a summation of all observations dropped is equal to the total loss in the sample size.

${ }^{23}$ These people have missing proxies for the main variables of this paper.

${ }^{24}$ High school dropouts are a small group of outliers with a likely case of reverse causality between education and health (bad health leads to small education investment), which I wish to minimize.

${ }^{25}$ These deaths are most likely exogenous, since they were reasonably beyond the person's control.

${ }^{26}$ These diseases are likely to affect personality and lead to reverse causality between personality and health.

${ }^{27}$ To condition on the same starting age for everybody, and to make education a past event to minimize possible reverse causality.

${ }^{28}$ Four of five factors in this paper, childhood Conscientiousness and Extraversion, as well as adult Agreeableness and Neuroticism, were empirically shown to be correlated with the Big Five factors having the same names (Martin and Friedman, 2000). The Conscientiousness factor used in the final model of this paper is shown to be related to the Big Five Conscientiousness (with correlation 0.55, and $p$-value below 0.001). The
} 
In this paper, I extract personality factors based on exploratory factor analysis (EFA), which I perform on the psychological ratings from 1922. Exploratory factor analysis is a dimensionality-reducing statistical procedure widely used in psychometrics and other disciplines for finding a low-dimensional vector consisting of latent factors that explain multiple variables. The procedure, which is documented in Web Appendix A, makes it possible to find blocks of measures such that variables are closely correlated within blocks, but are uncorrelated or weakly correlated between blocks. Each block corresponds to one latent factor proxied by the multiple measures contained within the block. As a result of the exploratory factor analysis, I obtain three reliable personality factors for year 1922: Conscientiousness, Openness, and Extraversion. ${ }^{29}$ I borrow measures for the adulthood factors of year 1940-Neuroticism and Agreeableness - from a companion paper (Gensowski, Heckman, and Savelyev, 2011). According to John and Srivastava (1999), Openness describes the breadth, depth, originality, and complexity of individual's mental and experimental life; Extraversion implies an energetic approach to the social and material wold and includes traits such as sociability, activity, assertiveness, and positive emotionality; Neuroticism contrasts emotional stability and even-temperedness with negative emotionality, such as feeling anxious, nervous, sad, and tense. Finally, Agreeableness contrasts a proposal and communal orientation towards others with antagonism and includes traits such as altruism, tendermindedness, trust, and modesty. I provide definitions of Conscientiousness in the following section.

authors also show a relationship of their Sociability with the Big Five Extraversion (with correlation 0.40, and $p$-value below 0.001). Extraversion in this paper is defined similar to the authors' Sociability (see Table A-8 of the Web Appendix), and, hence, should also be related to the Big Five Extraversion. Openness, as defined in this paper was not compared with Big Five Openness by Martin and Friedman (2000), but it should be related to the Big Five Openness from theoretical considerations.

${ }^{29}$ As we know, it is up to the researcher to determine how to label factors obtained by exploratory factor analysis. Interpretation of factors is derived from the interpretation of their measures. See Table 3 for the list of factors and their measures. 
Understanding Conscientiousness Conscientiousness is the only noncognitive trait among the five near-Big Five traits that show statistically significant effects in this paper. ${ }^{30}$ Moreover, Conscientiousness affects both education and longevity, not just one of them. John and Srivastava (1999) define Conscientiousness as "individual differences in the propensity to follow socially prescribed norms for impulse control, to be task- and goal- directed, to be planful, to delay gratification, and to follow norms and rules." Alternatively, Conscientiousness can be described as the "propensity to be organized, controlled, industrious, responsible, and conventional" (Roberts et al., 2009).

A growing body of evidence shows that personality traits develop both during childhood and afterwards. Helson et al. (2002) and Roberts et al. (2005) provide a comprehensive overview of the debate surrounding personality trait development. Using a cross-sectional evaluation of Conscientiousness by age, Srivastava et al. (2003) show that Conscientiousness increases throughout early and middle adulthood at varying rates. Roberts et al. (2006) conducts a meta-analysis of longitudinal studies, showing continuous changes in personality throughout life. Conscientiousness increases the most when people are in their 20s and 30s.

The biological view of psychology still contends that developments of personality in adulthood are predetermined by biologically based, psychological tendencies (e.g., McCrae et al., 2000.), but the traditional view of personality as pre-determined, stable, and non-malleable has been challenged by recent literature. Roberts and Bogg (2004) provide evidence showing that Conscientiousness and socioenvironmental factors influence and affect each other. Conscientiousness may change as a result of marriage or employment. Roberts et al. (2003) shows the relationship between work experience and personality changes, including selfcontrol, harm avoidance, and traditionalism, which are closely related to Conscientiousness.

\footnotetext{
${ }^{30}$ Statistically insignificant effects are characterized by a combination of high p-values and low coefficients. Omitting variables showing these statistically insignificant effects leads to virtually no change in estimated coefficients and to a large decline in AIC, since accounting for latent traits consumes many degrees of freedom. Table B-10 of the Web appendix shows that the AIC of a three-factor model of longevity accounting for Conscientiousness, Openness, and Extraversion is about twice as big as the AIC of a one-factor model accounting for Conscientiousness only. The cognitive trait measured by IQ affects education choice at lower levels of education, but the effect of cognition on longevity is not statistically significant.
} 
Heckman, Malofeeva, Pinto, and Savelyev (2011) show experimental evidence that externalizing behavior, which is closely related to Conscientiousness, can be strongly enhanced at ages 3-4 through educational intervention, at least for disadvantaged children, with major consequences for later life outcomes.

If personality traits are malleable during and after childhood, policy interventions with regards to parenting and counseling may be able to help foster the growth of Conscientiousness. Piedmont (2001) reports that the outpatient counseling in a drug rehabilitation program showed significant shifts of the Big Five dimensions during and even after the intervention. Milgram and Toubiana (1999) and Pychyl et al. (2002) suggest that parenting styles influence procrastination, which is strongly related to child Conscientiousness. Finally, Forgatch and DeGarmo (1999) suggest that effective parenting practices can improve a child's adjustment at school, which may well affect a child's Conscientiousness. There is thus a sizable body of evidence indicating that Conscientiousness is malleable in both childhood and adulthood. If there is also evidence that Conscientiousness is an important determinant of education, health, and longevity, as the findings in this paper suggest, then fostering Conscientiousness is a valid policy concern.

Conscientiousness and IQ Current literature suggests that while IQ is related to Openness, IQ and Conscientiousness are unrelated and so a selection on IQ doesn't lead to a selection on Conscientiousness. In line with this claim, Ackerman and Heggestad (1997) show that the correlation of General Intelligence with Conscientiousness is both low (0.02) and statistically insignificant, whereas the correlation with Openness is sizable (0.33) and statistically significant. Similarly, the study by DeYoung et al. (2005) reports that the correlations between measures of Intelligence and Conscientiousness are generally statistically insignificant, while measures of Openness and Intelligence show statistically significant correlation $(p<.01)$. Some recent studies suggest that there is a negative association between IQ and Conscientiousness. The main rationale behind this claim is that people with low 
IQ have a higher need to develop Conscientiousness (Moutafi et al., 2004). This idea has motivated research of relationships among Conscientiousness, intelligence and academic or professional success, as in Farsides and Woodfield (2003). While these claims deserve attention, a direct relationship between Conscientiousness and IQ has neither been proven nor widely accepted. Conversely, various papers continue to suggest that the relationship between IQ and Conscientiousness is either weak or non-existent. For instance, a recent study by Borghans et al. (2011) confirms a strong relationship between IQ and Openness, and finds no relationships between IQ and Conscientiousness. For the Terman sample, I find that IQ and Conscientiousness are also uncorrelated (see Table B-12 of the Web Appendix).

\section{Methodology}

\subsection{Economic Model}

The econometric model used in this paper is motivated by a version of the discrete life cycle economic model with time horizon $T$ years and uncertain duration of life (Becker, 2007). I incorporate Conscientiousness into Becker's model as an exogenous parameter: individuals cannot choose their levels of Conscientiousness, but Conscientiousness can possibly be influenced by parents and educators. ${ }^{31}$ Consider a time-separable expected utility function

$$
U=\sum_{t=0}^{T} B^{t}(\theta) \cdot S_{t}(\theta) \cdot u_{t}\left(x_{t}, l_{t}\right)
$$

where $B$ is the discount rate, $S_{t}$ is the unconditional survival probability through age $t$ for $t=1, \ldots, T, S_{0}=1,{ }^{32}$ and $u_{t}\left(x_{t}, l_{t}\right)$ is the utility function at age $t$ determined by consumption $x_{t}$ and leisure $l_{t}$. Let the discount rate, $B$, depend on Conscientiousness $\theta$ as confirmed by

\footnotetext{
${ }^{31}$ See Section 3 for a discussion of the growing evidence that Conscientiousness is malleable.

${ }^{32}$ The corresponding probability in the econometric model will be defined in formula (10).
} 
Daly et al. (2009). ${ }^{33}$ Let survival $S_{t}$ depend on years of education $D^{34}$ and Conscientiousness $\theta .^{35}$

Consider a two-period model, which demonstrates the main features of the economic problem and is easily generalizable to a multiple-period case using utility specification (1) with a multiple-period budget constraint similar to a two-period constraint (3). Let capital and annuity markets be perfect and earnings not be taxed. An individual maximizes the expected utility

$$
U\left(x_{0}, x_{1}, l_{0}, l_{1}, D ; \theta\right)=u_{0}\left(x_{0}, l_{0}\right)+B(\theta) \cdot S_{1}(D, \theta) \cdot u_{1}\left(x_{1}, l_{1}\right)
$$

with respect to consumption $\left\{x_{0}, x_{1}\right\}$, leisure $\left\{l_{0}, l_{1}\right\}$, and education $D$, subject to the intertemporal budget constraint ${ }^{36}$

$$
x_{0}+f(D, \theta)+\frac{S_{1}(D, \theta) \cdot x_{1}}{(1+r)}=w_{0}(\theta) \cdot\left(1-l_{0}\right)+\frac{S_{1}(D, \theta) \cdot w_{1}(D, \theta) \cdot\left(1-l_{1}\right)}{(1+r)}
$$

where $w_{0}(\theta)$ and $w_{1}(D, \theta)$ are wages in period 0 and 1 , and where the cost of education investment, $f(D, \theta)$, depends on years of education and Conscientiousness.

Assume that (a) $\partial w_{0} / \partial \theta>0$, (b) $\partial w_{1} / \partial \theta>0$, (c) $\partial B / \partial \theta>0$, (d) $\partial^{2} f / \partial D \partial \theta<0$, (e)

\footnotetext{
${ }^{33}$ In this simple model, I also abstract from a hypothetical possibility in line with (Becker and Mulligan, 1997) that individuals may rationally invest in their Conscientiousness $\theta$ with the aim of reducing the discount on future utilities.

${ }^{34}$ The model can be generalized to use discrete schooling $D$, as in the rest of the paper, at the expense of losing the option to differentiate with respect to education.

${ }^{35}$ Literatures in health economics and in psychology establish positive relationships between education and health (Grossman and Kaestner, 1997), and between conscientiousness and health (Bogg and Roberts, 2004; Hampson and Friedman, 2008).

${ }^{36}$ In the present simple model, investments in health operate indirectly through investments in education. In contrast, in Grossman's (1972) model, individuals directly invest in health. I leave generalizations of the current theoretical and empirical analysis for future research based on data better suited for studying direct health investments.
} 
$\partial^{2} S_{1} / \partial D \partial \theta<0$, and (f) $\partial^{2} w_{1} / \partial D \partial \theta<0 .{ }^{37}$ From the first-order conditions it follows that

$$
\begin{gathered}
\frac{\partial u_{0} / \partial l_{0}}{\partial u_{0} / \partial x_{0}}=w_{0}(\theta) \\
\frac{\partial u_{1} / \partial l_{1}}{\partial u_{1} / \partial x_{1}}=w_{1}(D, \theta) \\
\partial u_{0} / \partial x_{0}=(1+r) \cdot B(\theta) \cdot \partial u_{1} / \partial x_{1} \\
\frac{1}{1+r} \cdot S_{1}(D, \theta) \cdot \frac{\partial w_{1}(D, \theta)}{\partial D} \cdot\left(1-l_{1}\right)+\frac{1}{1+r} \cdot B(\theta) \cdot \frac{\partial S_{1}(D, \theta)}{\partial D} \cdot \frac{u_{1}}{\partial u_{1} / \partial x_{1}}= \\
\frac{\partial f(D, \theta)}{\partial D}+\frac{1}{1+r} \cdot \frac{\partial S_{1}(D, \theta)}{\partial D}\left[x_{1}-w_{1}(D, \theta) \cdot\left(1-l_{1}\right)\right] .
\end{gathered}
$$

Equations (4) and (5) coupled with assumptions (a) and (b) imply that higher Conscientiousness leads to higher compensated (i.e. Hicksian, utility-constant) labor supply ${ }^{38}$ in all periods of life. Equation (6) and assumption (c) imply that higher Conscientiousness leads to higher saving (or lower borrowing) in the early period of life.

Finally, equation (7) decomposes marginal costs and marginal benefits of education into several terms, all of which depend on Conscientiousness. Generally it is not clear whether these terms increase or decrease with Conscientiousness. Below, I discuss the terms of equation (7) on the high-hand-side (r.h.s), and on the left-hand-side (l.h.s.).

The first term on the r.h.s. is the marginal cost of education, which decreases with Conscientiousness by assumption (d). The second term is the discounted increase in the expected individual's budget deficit in the second period of life. While the marginal survival declines with Conscientiousness by assumption (e), the sign of the term is still unclear since, as predicted by equation (5) and assumption (b), consumption $x_{1}$, labor supply $\left(1-l_{1}\right)$, and

\footnotetext{
${ }^{37}$ Conscientiousness and Education tend to be substitutes. The response of wage to an increase in education should be higher for a less conscientious person than for a more conscientious person.

${ }^{38}$ The majority of leading experts in labor supply believe that the uncompensated (i.e. Marshallian) wage elasticity is either zero or positive (Fuchs et al., 1998), implying that the uncompensated labor supply is also likely increasing with Conscientiousness.
} 
wage $w_{1}$ all increase with Conscientiousness, making the sign of change of the expression in the square brackets indeterminant.

The first term on the l.h.s. represents the discounted higher wages obtained as a result of getting higher education. The second term represents the utility, increased as a result of higher survival rate. In the first term, the survival rate and labor supply positively depend on Conscientiousness, while the derivative of wage declines. In the second term, the survival rate $B(\theta)$ increases with Conscientiousness, while the marginal survival rate decreases by assumption (e), making the change of this term indeterminant too.

In summary, the model shows that Conscientiousness increases equilibrium levels of labor supply, consumption, and saving. Conscientiousness also affects the equilibrium choice of education, but the sign of this effect is not clear from the theoretical model without further assumptions. In the empirical part of the paper, I answer this question by showing that Conscientiousness enhances education $\partial D^{*} / \partial \theta>0$ (see Section 5). ${ }^{39}$

The model also demonstrates that knowing the properties of the survival function, such as derivatives and cross-derivatives of the function with respect to education and Conscientiousness, is essential for modeling intertemporal choices such as education and savings. In this paper, I estimate the survival function $S_{t}(D, \theta)$ and investigate its properties controlling for the endogenous education $D^{*}=D^{*}(\theta)$. I also provide empirical support for the assumption that $\partial^{2} S_{t}(D, \theta, X) / \partial \theta \partial D<0$, and show that $\partial S_{1}(D, \theta, X) / \partial \theta>0$ and $\partial S_{1}(D, \theta, X) / \partial D>0$

\subsection{Longevity Model}

From this section on, let $D$ be a categorical choice of the highest education level obtained in life. $D$ takes values from 1 to 5: (1) High school graduate, (2) Some college, (3) Bachelor's degree, (4) Master's degree, and (5) Doctorate.

\footnotetext{
${ }^{39} \mathrm{~A}$ positive correlation between Conscientiousness and higher education of high ability individuals was found in the literature (Martin et al., 2007). This paper identifies the effect conditional on a comprehensive set of background variables.
} 
The discrete time hazard function $h_{t}$ is the conditional probability that a person's death occurs at age $t$ (event $T=t),{ }^{40}$ given that a person has survived to that age (event $T \geq t$ ). Let the hazard function depend on schooling $D$, other observables $\boldsymbol{X}$, and latent Conscientiousness $\theta$ :

$$
h_{t}=\mathbb{P}(T=t \mid T \geq t, D, \theta, \boldsymbol{X}) .
$$

The discrete time proportional odds model relates the conditional log-odds of the hazard $h_{t}$ to covariates and a time-specific intercept ${ }^{41} \delta_{t}$ (Cox, 1972). An advantage of this model over a continuous time proportional hazard model is that the proportionality assumption can be easily relaxed by allowing for age-varying regression coefficients. ${ }^{42}$ Consider the following specification for the proportional odds model with an age-varying coefficient for education: ${ }^{43}$

$$
\ln \left(\frac{h_{t}}{1-h_{t}}\right)=\sum_{d \neq 2} \boldsymbol{\alpha}_{d t} \cdot 1(D=d)+\sum \boldsymbol{\beta}_{d} \cdot 1(D=d) \cdot \theta+\boldsymbol{\gamma} \boldsymbol{X}+\delta_{t}
$$

where $1(D=d)$ is a random indicator that a person is at education level $d$, and $\alpha_{d t}$ are time-dependent coefficients. ${ }^{44}$

The unconditional survival probability through age $\tau$ is given by a product of conditional survival functions: ${ }^{45}$

$$
S_{\tau} \mid D, \theta, \boldsymbol{X}=\prod_{t=1}^{\tau}\left(1-h_{t}\right)
$$

\footnotetext{
${ }^{40} \mathrm{~A}$ random age of death is denoted by $T$.

${ }^{41}$ This discrete time hazard model uses full years of life as a measure of survival: once a person reaches his birthday, he survives to the next age of life.

${ }^{42}$ In an exploratory analysis, I found that for a similar continuous time proportional hazard model, the proportional hazard test is rejected with respect to education variables. An additional advantage of the discrete time model, which I do not employ in the current paper but plan to employ in later research, is that age-varying regressors can be used (Muthen and Masyn, 2005; Singer and Willet, 1993).

${ }^{43}$ The reference category of education is some college education denoted as $1(D=2)$.

${ }^{44}$ In this model, $\boldsymbol{\alpha}_{d t}$ depends on time $t$ only for $d=1$ and $d=5$ in order to relax the proportional odds assumption precisely for those variables for which the assumption is violated, as I found based on preliminary estimation.

${ }^{45} S_{\tau}$ is traditionally called "unconditional survival probability." This term might be confusing, since the probability is still conditional on being alive at starting point $t=0$, which, in this paper, corresponds to being alive at one's $31^{\text {st }}$ birthday. Hence, $t=1$ corresponds to survival through age 31 , while $\tau$ corresponds to survival through age $\tau+30$, which can also be phrased as survival to age $\tau+31$. For instance, once a person has reached his $81^{\text {st }}$ birthday, he has survived through age 80 , and to age 81 .
} 
Then, for an average person from the population, the survival conditional on education and Conscientiousness is given by

$$
S_{\tau} \mid D, \theta=\int \prod_{t=1}^{\tau}\left(1-h_{t} \mid \boldsymbol{X}=\boldsymbol{x}\right) d F_{\boldsymbol{X}}(\boldsymbol{x})
$$

\subsection{Education Choice Model}

I use a generalized ordered logit model for studying schooling choice, since more parsimonious ordered choice models proved to be poorly specified. ${ }^{46}$ The model specifies conditional probabilities of choosing each level of education as

$$
\mathbb{P}(D>d \mid \theta, \boldsymbol{X})=g\left(a_{d}+\boldsymbol{X} \boldsymbol{b}_{\boldsymbol{d}}\right)=\frac{\exp \left(a_{d}+\boldsymbol{X} \boldsymbol{b}_{\boldsymbol{d}}\right)}{1+\exp \left(a_{d}+\boldsymbol{X} \boldsymbol{b}_{\boldsymbol{d}}\right)},
$$

so that

$$
\begin{gathered}
\mathbb{P}(D=1 \mid \theta, \boldsymbol{X})=1-g\left(a_{1}+\boldsymbol{X} \boldsymbol{b}_{\mathbf{1}}\right) \\
\mathbb{P}(D=d \mid \theta, \boldsymbol{X})=g\left(a_{d-1}+\boldsymbol{X} \boldsymbol{b}_{\boldsymbol{d}-\mathbf{1}}\right)-g\left(a_{d}+\boldsymbol{X} \boldsymbol{b}_{\boldsymbol{d}}\right), d=2,3 \\
\mathbb{P}(D=4 \mid \theta, \boldsymbol{X})=g\left(a_{4}+\boldsymbol{X} \boldsymbol{b}_{\mathbf{4}}\right) .
\end{gathered}
$$

\subsection{Latent Factor Model}

In order to account for personality variables as determinants of longevity and schooling choice it is a natural to use a factor model ${ }^{47}$ as an integral component of longevity and schooling models. In Web Appendix A, I show that available childhood personality measures well proxy three personality factors: Conscientiousness, Openness, and Extraversion. In a

\footnotetext{
${ }^{46}$ For the ordered logit model, the Brant test (Brant, 1990) of the parallel regression assumption is rejected. This is a test of equality of coefficients of a number of binary logit models (4 binary models in this paper with 5 education categories) implied by the the ordered logit model. I also find that for a multinomial logit, which is a potential alternative to the generalized ordered logit, the independence of irrelevant alternatives assumption is not satisfied. Therefore, I use a generalized ordered logit.

${ }^{47}$ Factor models are designed for obtaining a small number of latent factors based on multiple noisy and correlated observable variables (e.g., Bollen (1989)).
} 
companion paper, Gensowski, Heckman, and Savelyev (2011) identify, among others, two more factors: adulthood Agreeableness and Neuroticism. However, as mentioned above, only Conscientiousness is predictive of longevity and education, while other traits consume many degrees of freedom without contributing to the model fit. ${ }^{48}$ Therefore, I use only one latent factor, Conscientiousness, in the final model specification. As follows from Web Appendix A, Conscientiousness is well proxied by four measures, namely "prudence and forethought," "conscientiousness," "truthfulness," and "freedom from vanity and egoism." There are the same measures of Conscientiousness that psychologists found in earlier studies (Friedman et al., 1993). These measures are related to the Big Five Conscientiousness, but to a different degree. ${ }^{49}$ The model below accounts for the different degrees of relation of these measures to Conscientiousness by allowing different coefficients $\psi_{k}$ relating measures $M_{k}$ to factor $\theta$. By estimating the factor model, I explicitly account for measurement error in proxies, thus avoiding the attenuation bias.

The part of the model capturing the latent factor is defined by the following linear equations: ${ }^{50}$

$$
M_{k}=\psi_{k} \theta+\omega_{k} \boldsymbol{X}+\eta_{k}
$$

where $M_{k}, k=1, \ldots, 4$, are measures of the latent factor $\theta,{ }^{51}$ with error terms $\eta_{k} \Perp \eta_{k^{\prime}}$ for all $k \neq k^{\prime}, \theta \Perp \eta_{k}$ for all $k=1, \ldots, 4$. In addition, $\mathbb{E}\left(\eta_{k}\right)=0$ for all $k$, and $\mathbb{E}(\theta)=0$. Equations (16) have no intercepts, since all measures are standardized for the estimation sub-sample. ${ }^{52}$

\footnotetext{
${ }^{48}$ Table B-10 of the Web Appendix confirms that a one-factor model controlling for Conscientiousness is preferable to a three-factor model by comparing AIC and BIC statistics, which are about twice as large for the three-factor model. For more information about Conscientiousness, see Tables 1 and 3.

${ }^{49}$ As already reported above, the Big Five Conscientiousness is briefly defined as "... the propensity to follow socially prescribed norms for impulse control, to be task- and goal- directed, to be planful, to delay gratification, and to follow norms and rules" (John and Srivastava, 1999). "Prudence" and "conscientiousness" are directly related to this definition. "Freedom from vanity and egoism" as well as "truthfulness" are related not only to to Conscientiousness (following socially accepted norms of behavior), but also, perhaps, to Agreeableness (Friedman et al., 1995). See Figure 12 for different shares of signal in measures of Conscientiousness ranging from $20 \%$ (for "freedom from vanity") to $77 \%$ (for "conscientiousness").

${ }^{50}$ As shown by Cunha et al. (2010), it is theoretically possible to identify a general nonlinear factor model. However, given the relatively small sample size, a standard linear factor model is optimal for this paper.

${ }^{51}$ Measures of Conscientiousness used for model estimation are presented in Table 3.

${ }^{52} \mathrm{~A}$ standardized measure $M$ is obtained from a raw measure $M^{\prime}$ by a linear transformation: $M=$ $\left(M^{\prime}-\bar{M}^{\prime}\right) / s d\left(M^{\prime}\right)$, where $\bar{M}^{\prime}$ and $s d\left(M^{\prime}\right)$ denote a mean and a standard deviation of the raw measure.
} 
As a standard mean to achieve identification, $\psi_{1}$ is normalized to one.

\subsection{Model Estimation}

For a subject $i$, who is right-censored at age $t_{i},{ }^{53}$ we only know that he was still alive at the time of censoring $\left(T_{i}>t_{i}-1\right)$. The ex-ante probability of such event is

$$
\mathbb{P}\left(T_{i}>t_{i}-1\right)=\prod_{j=1}^{t_{i}-1}\left(1-h_{i j}\right)
$$

For the uncensored subjects, ${ }^{54}$ we know that $T_{i}=t_{i}$ with probability

$$
\mathbb{P}\left(T_{i}=t_{i}\right)=h_{i t_{i}} \prod_{j=1}^{t_{i}-1}\left(1-h_{i j}\right)
$$

Hence, we can form a likelihood function $L=\prod_{i=1}^{n} l_{i}$, such that

$$
l_{i}=\left(h_{i t_{i}}\right)^{\xi_{i}} \prod_{j=1}^{t_{i}-1}\left(1-h_{i j}\right)
$$

where $\xi_{i}$ is 1 if the individual is uncensored, and 0 if he is right-censored. In order to account for latent factor $\theta$ as a determinant of the hazard function $h_{t}$, I use maximum likelihood estimation based on the EM algorithm (e.g., Muthen and Masyn, 2005).

\subsection{Treatment Effect Calculation}

\subsubsection{Overcoming Endogeneity and Reverse Causality}

As mentioned earlier, there are two major statistical problems that prevent us from interpreting correlation between education and longevity as causal effect (e.g., Grossman, 2000):

Such standardization is a standard technique in psychometrics (Allen and Yen, 2002).

${ }^{53}$ Right-censored subjects are those who either dropped out during the course of the study or were alive by the end of the study.

${ }^{54}$ The uncensored subjects are those who died during the course of the study. 
(1) a possible existence of confounding factors that affect both education and longevity, and (2) a possibility of reverse causality (expected longevity may affect education). In this paper, I address both problems in order to separate out the causal effect of education on longevity. Instead of relying on instrumental variables, I employ an alternative method that relies on the extraordinary richness of Terman data, both in terms of background variables and in terms of proxies of psychological traits. Due to this richness, I base the identification of causal effects in this paper on the assumption that, conditional on background characteristics, all dependence across longevity outcomes, education choices, and measures comes from cognitive and noncognitive traits. This is the same identification assumption as in Heckman, Stixrud, and Urzua (2006). The background characteristics, $\boldsymbol{X}$, include early health, private tutoring, World War II experience, and detailed family background information (see Table 2). This identifying assumption resembles the matching assumption, but it involves a latent factor. If the latent factor were observed, it would be possible to apply a standard matching procedure. Since it is not observed, I account for the latent factor in a parametric factor model. Even though the data provide measures of many latent factors, only the factor of Conscientiousness is identified as confounding and needs to be controlled for.

To address the reverse causality problem, I employ three measures. First, I drop all subjects who had severe medical conditions early in their life. Second, I control for measures of early health, so that the effect of education is measured conditional on health, which is a potential predictor of longevity. Finally, I restrict consideration to longevity after 30, which rules out people in poor health who died early and were likely subject to reverse causality. For people who died after age 30 , education is a past event. ${ }^{55}$

Even though it is generally impossible to fully account for confounding factors and reverse causality, I believe that the extraordinary richness of Terman data combined with methods described above makes effects of confounding factors and reverse causality negligible.

\footnotetext{
${ }^{55}$ Only $2.3 \%$ of respondents were still at school at age 30 .
} 


\subsubsection{Treatment Effect of Education}

According to formula (10), the treatment effect of changing education from level $d$ to level $d^{\prime}$ on the probability of survival through age $\tau$ for a person with Conscientiousness $\lambda$ and background $\boldsymbol{x}$ will be

$$
\Delta_{\tau}\left(d, d^{\prime}, \lambda, \boldsymbol{x}\right)=\left(S_{\tau} \mid D=d, \theta=\lambda, \boldsymbol{X}=\boldsymbol{x}\right)-\left(S_{\tau} \mid D=d^{\prime}, \theta=\lambda, \boldsymbol{X}=\boldsymbol{x}\right) .
$$

The average treatment effect of education on the unconditional survival probability through age $\tau$ for a random person from the Terman population is thus ${ }^{56}$

$$
\Delta_{\tau}\left(d, d^{\prime}, \lambda\right)=\int \Delta_{\tau}\left(d, d^{\prime}, \lambda, \boldsymbol{x}\right) d F_{\boldsymbol{X}}(\boldsymbol{x})
$$

We can also obtain the unconditional average treatment effect by integrating (20) over the joint distribution of Conscientiousness and background variables:

$$
\Delta_{\tau}\left(d, d^{\prime}\right)=\int \Delta_{\tau}\left(d, d^{\prime}, \lambda, \boldsymbol{x}\right) d F_{\theta}, \boldsymbol{X}(\lambda, \boldsymbol{x})
$$

This effect based on the full model (model 1) can be compared with the effect calculated for a partial model (model 2) that does not account for Conscientiousness but accounts for background variables

$$
\tilde{\Delta}_{\tau}\left(d, d^{\prime}\right)=\int \tilde{\Delta}_{\tau}\left(d, d^{\prime}, \boldsymbol{x}\right) d F_{\boldsymbol{X}}(\boldsymbol{x})
$$

where

$$
\tilde{\Delta}_{\tau}\left(d, d^{\prime}, \boldsymbol{x}\right)=\left(\tilde{S}_{\tau} \mid D=d, \boldsymbol{X}=x\right)-\left(\tilde{S}_{\tau} \mid D=d^{\prime}, \boldsymbol{X}=x\right),
$$

and with the effect calculated for another partial model (model 3) that accounts neither for

\footnotetext{
${ }^{56}$ This model is based on the conditional independence assumption, which implies no selection effect after controlling for latent traits. Therefore, within this model, there is no difference among such parameters as the average treatment effect (ATE), the effect of treatment on the treated (TT), and the effect of treatment on the untreated (TUT) (Heckman and Vytlacil, 2007).
} 
background variables nor for Conscientiousness

$$
\hat{\Delta}_{\tau}\left(d, d^{\prime}\right)=\left(\hat{S}_{\tau} \mid D=d\right)-\left(\hat{S}_{\tau} \mid D=d^{\prime}\right)
$$

Here $\tilde{S}_{\tau}$ and $\hat{S}_{\tau}$ are analogous to $S_{\tau}$ in formula (10), but are based on hazards $\tilde{h}_{t}$ and $\hat{h}_{t}$ calculated for partial models 2 and 3.

\subsubsection{Direct, Indirect and Total Treatment Effects of Conscientiousness}

For a random person from the Terman population assigned to education $d$, the expected survival probability as a function of Conscientiousness can be written as

$$
p_{\tau}(\lambda)=\int \sum_{d=1}^{5} \mathbb{P}(D=d \mid \theta=\lambda, \boldsymbol{X}=\boldsymbol{x})\left(S_{\tau} \mid D=d, \theta=\lambda, \boldsymbol{X}=\boldsymbol{x}\right) d F_{\boldsymbol{X}}(\boldsymbol{x}) .
$$

The total effect of Conscientiousness can be decomposed into the direct and the indirect effects:

$$
\begin{aligned}
& \underbrace{\frac{d p_{\tau}(\lambda)}{d \lambda}}_{\text {total effect }}= \\
& \underbrace{\int \sum_{d=1}^{5} \mathbb{P}(D=d \mid \theta=\lambda, \boldsymbol{X}=\boldsymbol{x}) \frac{\partial}{\partial \lambda}\left(S_{\tau} \mid D=d, \theta=\lambda, \boldsymbol{X}=\boldsymbol{x}\right) d F_{\boldsymbol{X}}(\boldsymbol{x})}_{\text {direct effect }} \\
& \underbrace{\int \sum_{d=1}^{5} \frac{\partial}{\partial \lambda} \mathbb{P}(D=d \mid \theta=\lambda, \boldsymbol{X}=\boldsymbol{x})\left(S_{\tau} \mid D=d, \theta=\lambda, \boldsymbol{X}=\boldsymbol{x}\right) d F_{\boldsymbol{X}}(\boldsymbol{x})}_{\text {indirect effect }} .
\end{aligned}
$$

The indirect effect represents enhanced survival probability induced by a higher level of education, which is, in turn, induced by higher Conscientiousness. The direct effect represents the part of the effect of Conscientiousness that is unrelated to enhanced education. 


\section{$5 \quad$ Empirical Results}

\subsection{Descriptive Results}

Figure 2 shows nonparametric estimates of survival $S_{\tau}$ by education and gender. For males, higher levels of education correspond to increased longevity. For females, no substantial difference is observed between the survival curves. Although the survival curve for the sample of 27 females with doctoral degrees differs from the other curves, the sample size is too small to make the statistical inference that this curve is below the others. ${ }^{57}$ Indeed, Figure 3 of the main paper and Figures D-2-D-7 of the Web Appendix show that we cannot statistically distinguish between survival curves for females with different education, while survival curves for males generally differ significantly, especially at older ages. Survival curves plotted for various levels of Conscientiousness, with higher Conscientiousness corresponding to higher longevity, also differ more for males than for females (see Figure 4).

Figure 5 displays the association between Conscientiousness and education by showing kernel densities of factor scores by education. ${ }^{58}$ Generally, densities for higher levels of education are shifted to the right. An exception is Conscientiousness of males with some college, for whom the kernel density is, on average, much lower than that of high school graduates. ${ }^{59}$ Another exception is the Conscientiousness of females with a doctorate: the mean of their Conscientiousness is to the left of the corresponding means for both females

\footnotetext{
${ }^{57}$ In Appendix C, I show that having a doctoral degree for females born, on average, in 1910, is associated with lower family life satisfaction, lower general happiness, and fewer children. Some of these factors, along with relatively low Conscientiousness of females with a doctorate (see Figure 5), could be behind this unusual, but not statistically confirmed, pattern. I found no evidence that females with a doctorate degree were less likely to be married or more likely to be divorced than other females. Moreover, the Terman data suggest that being single is associated with higher mortality for males but not for females (see Figure D-8 of the Web Appendix).

${ }^{58}$ See also Figures D-10 and D-11 of the Web Appendix for similar displays for IQ, Openness, and Extraversion.

${ }^{59}$ Males with some college education went to college but did not get a bachelor's degree despite their exceptional IQ. Low Conscientiousness may partly explain this outcome. This result is similar to that by Heckman, who showed that high school drop-outs, even those with GED certificates, have low non-cognitive skills. Thus, there is a similarity between high-IQ college drop-outs and high school drop-outs from the general population.
} 
with bachelor's and master's degrees. ${ }^{60}$ While distributions of traits by education demonstrate gender-specific features, there are no sizable gender differences in overall distributions of traits by gender (see Figure D-9 of the Web Appendix).

\subsection{Results of Longevity, Education, and Measurement Models}

I first discuss results on the scale of estimation, namely estimated model coefficients. Afterwards, I proceed with results on the scale of interest, such as the probability of survival through age 70 and its dependence on education and Conscientiousness. Results on the scale of interest are directly interpretable, while the results on the scale of estimation are harder to interpret, especially for nonlinear models.

The econometric model in this paper estimates the technology of human survival graphically displayed in Figure 1. In this model, latent Conscientiousness affects the hazard of death both directly and indirectly. The indirect channel operates through the change in education induced by a change in Conscientiousness. The direct channel summarizes all causal links from Conscientiousness to survival, excluding the education channel.

Model Estimates Estimates for the proportional odds model of mortality hazards (see equations (8), (9), and (16)) are presented in Tables $4-5$ of the main paper. ${ }^{61}$ Negative coefficients in the tables imply a lower hazard of death and, thus, greater longevity. The tables include estimates for the full model (model 1), as well as for three partial models that are misspecified by omitting various right-hand-side variables (models $2-4$ ). Tables $4-5$ also show the proportional odds test $p$-values for model 1 . The $p$-values of the test are large, implying that we cannot reject the current model specification. ${ }^{62}$

\footnotetext{
${ }^{60}$ This curve is for a very small and unusual group of 27 females. These women chose to obtain a doctorate at times when professional occupations were dominated by males and when females with doctorates had poor chances in the marriage market. Figure D-11 of the Web Appendix suggests that they had, on average, very high IQ and Openness but not particularly high Conscientiousness.

${ }^{61}$ Tables $4-5$ show estimates for the key variables only. Estimates for background controls and for the measurement system are presented and described in the Web Appendix (see Tables B-1-B-3).

${ }^{62}$ The proportional odds test is a likelihood ratio test. The current (restricted) model with a constant regression coefficient over time is compared with an unrestricted model, where the regression coefficient is
} 
The "model 1" panel of Table 4 shows that both education and Conscientiousness decrease the odds ratio of the hazard of death for males. All else being equal, the estimates suggest that there is a negative and statistically significant effect of exogenously varied education ${ }^{63}$ on the hazard-of-death odds ratio at the average level of Conscientiousness. ${ }^{64}$ We also see that Conscientiousness decreases the odds of the hazard of death, although that effect is only statistically significant at lower levels of education (high school diploma, some college, and bachelor's degree). ${ }^{65}$

Misspecified models 2-4 in Table 4 are presented for comparison with model 1. For education levels above some college, the estimated effects of education are generally stronger in absolute value for models 2-4 than for model 1 . Clearly, model 1 eliminates the upward omission bias by accounting for a set of control variables, some of which are correlated with both education and health. Coefficients for the high school diploma variable show opposite trends when comparing model 1 with models 2 and 3, for which Conscientiousness is omitted. This finding is expected because of the inverse relationship between Conscientiousness and the choice of some college education over a high school diploma for males (see Figure 5, panel (a)).

Estimates for females are generally statistically insignificant (see Table 5). As with males, Conscientiousness decreases the odds of the hazard of death for females with some college. However, the effects of Conscientiousness for women with a high school diploma or a bachelor's degree are not precisely determined. ${ }^{66}$ Gender differences are consistent allowed to change freely over time. High $p$-values indicate that the specification of the current parsimonious model is sufficiently good.

${ }^{63}$ I allowed age-dependent coefficients for the effects of high school education and the doctorate. Based on preliminary estimation, I discovered that the proportional odds test is rejected unless I allow for agedependence, and that at least three time intervals with distinct coefficients are needed to in order to make sure that the the proportional odds test is not rejected. I considered various alternative splits of the lifetime into three to seven time intervals, and found that a split 30-59, 60-69, and 70-up corresponds to the best AIC and BIC goodness-of-fit statistics (see Table B-11 of the Web Appendix).

${ }^{64}$ The average level of Conscientiousness is zero as a result of normalization.

${ }^{65}$ I find that for this rather homogenous Terman sample of people with extraordinarily high IQ, IQ plays no role in predicting longevity, the same result as found earlier by Friedman et al. (1993). For greater efficiency, I do not control for IQ in the final model specification.

${ }^{66}$ In a simpler model with no Conscientiousness-education interaction (see Table B-13 of the Web Appendix), estimates of the effect of Conscientiousness are statistically significant for males but not for females, 
with results by Conti, Heckman, and Urzua (2010b), who show that both education and noncognitive traits matter more for males than for females in affecting health and health behaviors. In the Terman data, it is reasonable to expect gender differences to be stronger than in more contemporary data such as British Cohort Study used by Conti et al. (2011), since gender differences in the social acceptance of health behaviors such as smoking or drinking become less pronounced over time.

The education regression coefficients for females are generally not precisely determined. There are large positive coefficients for having a doctorate at ages 30-59 and 60-69, with the coefficients for ages 60-69 being statistically significant. This implies that females with a doctoral degree who were born at the beginning of the $20^{\text {th }}$ century have higher odds ratio of the death hazard than females with only some college, at least at ages $60-69 .{ }^{67}$

The effects of Conscientiousness and Cognition on the probabilities of schooling choices are shown in Table 6. For both males and females, educational attainment is increasing in Conscientiousness. Higher Conscientiousness of males leads to higher probabilities of obtaining education above some college, bachelor's degree, and master's degree. There is no effect of Conscientiousness on the probability of getting education higher than high school graduate. ${ }^{68}$ For females, Conscientiousness leads to higher probabilities of obtaining education above high school, some college, and bachelor, but not for obtaining a doctorate. ${ }^{69}$ IQ increases the probability of obtaining education above high school and above some college, but these effects are only statistically significant for males. All mentioned results are true for models with and without conditioning on background variables. ${ }^{70}$

which is in line with results accounting for the Conscientiousness-education interaction presented in Tables 4 and 5 .

${ }^{67}$ In Web Appendix C, I show that having a doctorate degree in this generation of females is associated with reduced family outcomes, which may explain this unusual pattern of the death-hazard odds ratio.

${ }^{68}$ No effect of Conscientiousness on the probability of obtaining education above high school graduate level can be explained by two opposite effects of Conscientiousness, which cancel each other: (1) a person is more likely to be a high school graduate than a college drop-out if Conscientiousness is higher (see Figure $5(\mathrm{a})$ ), and (2) a person is more likely to hold a bachelor's degree or above than a high school diploma if Conscientiousness is higher.

${ }^{69}$ No effect on obtaining a doctorate is in line with unusually low Conscientiousness of females with doctorates born approximately around 1910 (see Figure 5(b)).

${ }^{70}$ Coefficients associated with background variables are presented in Tables B- 8 and B- 8 of the Web 
Treatment Effect of Education In Figure 6, I show the effects of additional education of males on the probability of survival through ages varying from $\tau=40$ to 80 . All effects are relative to baseline education (High School) ${ }^{71}$ and conditional on survival through age $30^{72}$ based on formula (22). ${ }^{73}$

The treatment effects of education on longevity of males are generally large and statistically significant. The effects represent the increase in survival probability through a particular age, conditional on survival through age 30 . The effects increase up to age 70 and decline afterwards. At age 70, the effect of education varies from a 20 to a 30 percentage points increase in the probability of survival, depending on the final education level (compare panels (a)-(d) of Figure 6).

\section{Survival Conditional on Education and Conscientiousness Consider survival thor-} ough age 70 produced by the model as a function of education and Conscientiousness. ${ }^{74}$ The estimate of the survival function, represented by formula (11), is shown in Figure 7 . Each line in the figure corresponds to a particular level of education. The slope of each line represents the effect of Conscientiousness on survival. Numbers corresponding to each line show $p$-values for the effect of Conscientiousness. ${ }^{75}$ Based on these $p$-values, we can say that Conscientiousness has statistically significant effect at high school, some college, and Bachelor's degree, but not at Master's degree and Doctorate levels. While slopes represent the effect of Conscientiousness given education, vertical gaps between lines represent the causal effect of education given Conscientiousness.

Figure 7 allows us to derive some policy implications. First, education is most important

\footnotetext{
Appendix.

${ }^{71}$ The effects of additional education on longevity for people with baseline education higher than a high school diploma are generally statistically insignificant (see Figures D-21 and D-22 of the Web Appendix).

${ }^{72}$ As discussed above, conditioning on survival through age 30 is motivated by a completion of education by that age by almost all subjects, which makes education a past event. In Tables B-4-B-7 of the Web Appendix I show that results of the model are robust to the choice of age: regression coefficients and $p$-values for models with different initial ages are similar.

${ }^{73}$ Corresponding estimates for females are statistically insignificant. See Figure D-12 of the Web Appendix.

${ }^{74} \mathrm{At}$ age 70 , the effect of education on longevity is the strongest, as we see in Figure 6.

${ }^{75} \mathrm{P}$-values are taken from Table 4 .
} 
for increasing longevity when Conscientiousness is low. Arrow AB represents the effect of inducing a high school graduate with low Conscientiousness to get at least some college education below Bachelor's degree. The effect of this policy is a strong improvement in survival through age 30 from 30 to 55\%. Second, provided that Conscientiousness is indeed malleable, as discussed in Section 3, a transition represented by arrow AC leads to improvement of survival from 30 to 40\%. Finally, induced Conscientiousness can, in turn, induce higher educational attainment as represented by arrow $\mathrm{AC}$ inducing arrows $\mathrm{CD}, \mathrm{CE}$, and $\mathrm{CF}$. Later in this section I show that the induced indirect effect of Conscientiousness on survival is much smaller than the direct effect.

Treatment Effect of Education Conditional on Conscientiousness This section presents the effects of education relative to baseline High School level ${ }^{76}$ on survival of males through age 70 by deciles of Conscientiousness. ${ }^{77}$ In Figure 8, the bold solid curves represent the effects, while the thin dashed curves represent the $90 \%$ and the $95 \%$ bootstrap confidence intervals. The estimates are downward-sloping with Conscientiousness, implying that Conscientiousness is a substitute for education in producing longevity. Effects tend to be strong (25-50 percentage points) and statistically significant at low levels of Conscientiousness. However, at high levels of Conscientiousness, estimates decline to 17-22 percentage points, and are no longer statistically significant. The loss of significance usually occurs above the eighth decile of Conscientiousness (See panels (b)-(d) of Figure 8). The effect on longevity of obtaining some college education by a high school graduate (see panel (a) of Figure 8) is much smaller than the effects of obtaining the higher levels of education discussed above, since some college education is close to a high school education. This effect is only statistically significant at the $95 \%$ level only for deciles $3-5$ and at the $90 \%$ level for deciles $1-7$. Note, that "some college" is not a precisely determined level of education, which contributes to less precise estimates of the effect.

\footnotetext{
${ }^{76}$ The effects of additional education for males and females with higher baseline levels of education are generally statistically insignificant (see Figures D-14-D-20 in the Web Appendix).

${ }^{77}$ Results for females are not statistically significant at the 95\% level. See Figure D-13 of the Web Appendix.
} 
Direct, Indirect, and Total Effects of Conscientiousness Figure 9 shows the direct, indirect, and total effects of Conscientiousness on survival through age 70 calculated based on formula (27) for a random person from the Terman sample. The indirect effect of Conscientiousness is the Conscientiousness-induced change in longevity mediated by a change in the educational attainment. The direct effect of Conscientiousness is the causal effect of Conscientiousness going through all channels excluding the indirect channel of enhanced education. Finally, the total effect is the sum of the direct and the indirect effects (see Figure 1 for a scheme of the effects).

The effect is the change in survival probability, in percentage points, per one standard deviation change in Conscientiousness. From the first to the ninth decile of Conscientiousness, the estimates of the effects of Conscientiousness decline from 7.8 to 3.0 for the total effect, 6.5 to 3.3 for the direct effect, and 1.2 to -0.3 for the indirect effect. The declining indirect effect estimates ${ }^{78}$ can be explained by generally declining estimates of the effect of education that were previously discussed (see Figure 8 of the main paper and Figures D-14-D-16 of the Web Appendix). The direct effect appears to be declining, too. The total effect estimate is also declining, since it is a sum of declining direct and indirect effect estimates. Education is just one of several channels, such as healthy lifestyle, through which Conscientiousness affects longevity. Estimates suggest that the education channel might be sizable, although it is certainly not the only major channel through which Conscientiousness affects longevity.

Figure 10 presents each of the three curves from Figure 9, but with the $90 \%$ and the $95 \%$ bootstrap confidence intervals. The total effect of Conscientiousness (see panel (a)) is statistically significant at the $95 \%$ level for deciles $1-4$ and at the $90 \%$ level for deciles 1-6. The direct effect in panel (b) is not significantly different from zero at the $95 \%$ significance level, but is statistically significant for deciles $1-6$ at the $90 \%$ significance level. The indirect effect shown in panel (c) is not precisely determined..$^{79}$

\footnotetext{
${ }^{78}$ I cannot make any strong conclusions about the effect itself because of high standard errors.

${ }^{79}$ Similar decompositions for females are based on a smaller sample and are not precisely determined.
} 
Bias from Omitting Conscientiousness Figure 11 compares the estimated effect on survival through age 70 based on the full model ("model 1," see formula (22)) with the effects based on the partial models ("model 2" and "model 3," see formulas (23) and (25)). Model 2 does not account for Conscientiousness (see "omitted $\theta$ " bar), and model 3 accounts for neither Conscientiousness nor background variables (see "omitted $\theta$ and $x$ " bar).

Figure 11 also compares the bias from omitting Conscientiousness with the bias from omitting both Conscientiousness and background variables. The figure shows that a bias from omitting Conscientiousness only is about a half of the bias from omitting both Conscientiousness and background variables ( $15 \%$ bias), even though background variables include many essential controls such as parental education and occupation (see Table 2 for a full list of background variables).

\section{Discussion}

In this work, I establish the causal effect of education on the longevity of high-ability males. This is a contribution to the literature, as the causal status of higher education in health and longevity production has been controversial (e.g., Auld and Sidhu (2005); Grossman (2000, 2006); Grossman and Kaestner (1997); Lleras-Muney (2005)). In addition, I establish the role of a noncognitive factor, Conscientiousness, that affects both education and longevity and interacts with education in producing longevity. In the introduction, I mention how my findings are related to results in the literature. Below, I discuss this relationship in more detail.

There is no such thing as a single "causal effect of education on health" because the effect of education on health generally depends on level of education, level of cognitive and noncognitive traits, health and longevity measures, age, and gender. ${ }^{80}$ Every dataset has natural restrictions on what effects can be estimated and which methods can be used for

\footnotetext{
${ }^{80} \mathrm{I}$ consider longevity as one of possible measures of health, since death can be considered as an indicator of extremely poor health in the moment before death. A good property of this measure is that it is an objective measure unlike self-evaluated health.
} 
causal effect identification. Thus, we can only achieve a comprehensive understanding of education's causal status in producing health and longevity through the efforts of multiple researchers estimating this effect using a large variety of data and methodologies. This paper contributes to these efforts by filling in the gaps in our knowledge about the effects of higher education on longevity of high-ability individuals.

Results in the literature regarding the influence of cognitive ability and the attainment of higher education on the effect of education on health could be compared with results of this paper, which describes the effects of education conditional on high levels of ability. For instance, my results imply that generalizations of the main results of Auld and Sidhu (2005) should be made with caution. Auld and Sidhu (2005) use three health measures from the National Longitudinal Survey of Youth data: two binary health limitations and a general health index for the relatively healthy years below age 43. The authors arrive at a key conclusion that schooling beyond high school contributes very little to health. They also conclude that both schooling and cognitive ability are strongly related to health at their low levels, but are less related or unrelated at high levels. In contrast, my work shows that, even conditional on the top $0.4 \%$ of cognitive ability, education beyond high school strongly affects health of males, implying that even the highest IQs cannot fully substitute for education in producing health. ${ }^{81}$

This paper supplements results in the literature that show causal effects of education on health and longevity by using compulsory schooling laws as instruments (Adams, 2002; Arendt, 2005, 2008; Lleras-Muney, 2005; Silles, 2009; Spasojevic, 2003). All of these papers identify the effect of education on health at relatively low levels of education (below high school diploma). Among the papers cited above, only one paper is concerned with longevity (Lleras-Muney, 2005). The paper is based on the synthetic cohort assumption and identifies the causal effect of changes in compulsory education on longevity. ${ }^{82}$ My paper supplements

\footnotetext{
${ }^{81}$ On a separate note, Auld and Sidhu (2005) use the AFQT achievement test, not IQ. This suggests that the effect they observe may be partly due to Conscientiousness, since achievement tests are known to be largely dependent on personality (Borghans et al., 2011).

${ }^{82}$ Changes in compulsory education occurred in the range of $0-10$ years of schooling.
} 
the findings described above by identifying the effect of higher education on longevity. ${ }^{83}$ Furthermore, I do not rely on the synthetic cohort assumption, since the Terman dataset follows the same cohort for 70 years.

My results also confirm and supplement findings by Grossman (1975), who finds that post-high school education has strong effects on the health of middle-aged, white males from the top $50 \%$ of the cognitive ability distribution, ${ }^{84}$ even after controlling for a large number of background, economic, and early health variables. I confirm Grossman's findings by showing that even after eliminating the ability bias through controlling for IQ and latent personality factors, I still obtain strong and statistically significant effect of education on longevity. I also supplement Grossman's findings by discovering an interaction of education with Conscientiousness in affecting longevity.

Some of the results of this paper, such as the declining effects of education with Conscientiousness and gender differences, can be partly explained by recent results by Conti, Heckman, and Urzua (2010a,c) on the effect of education on health behaviors. These authors study the effects of latent cognitive and nocognitive factors on education, health, and health behaviors based on British cohort data. They show that the effects of post-compulsory education on health behaviors and health indicators vary with levels of early cognitive and noncognitive traits even at ages as young as 30. They find that the effects of post-compulsory education tend to be stronger when the level of a noncognitive trait is low. ${ }^{85}$ Smoking is an example of health behavior with such an outcome. Moreover, for some health behaviors and health outcomes such as the use of cannabis, depression, and general health, the authors find strong effects for males, but not for females, when a noncognitive trait is low.

\footnotetext{
${ }^{83}$ Higher education corresponds to about $13-20$ years of schooling.

${ }^{84}$ The men were volunteers, accepted as candidates to the Aviation Cadet status in 1943. The minimum passing score in the qualifying examination could be achieved by about one half of high school graduates (Grossman, 1975).

${ }^{85}$ The noncognitive scale of self-regulation that the authors use includes Locus of Control, Perseverance, Cooperativeness, Completeness, Attentiveness, and Persistence (Conti, Heckman, and Urzua, 2010a). Most of these measures should be related to Conscientiousness.
} 
Relation of this Paper to Work by Friedman and Co-Authors Howard Friedman and his co-authors have extensively studied the associations between personality and longevity and personality and health using the Terman data. They also investigated possible mechanisms behind these associations. In their recent book, Friedman and Martin (2011) summarize findings from papers by Friedman and co-authors. My results based on the same data but more elaborate methodology supplement findings by these authors.

I add to results by Friedman et al. by establishing the causal effect of higher education on longevity and the interaction between education and Conscientiousness in affecting longevity. In addition, I elaborate on earlier works by Friedman et al. by using a more elaborate statistical model, by exploring gender differences in the effects of education and Conscientiousness on longevity, and by testing the effect of childhood Openness on longevity.

As described in section 4, I use a discrete time proportional odds model. I find that for a continuous time Cox Proportional Hazard model, the proportional hazard assumption does not hold with respect to education variables. In the discrete time proportional odds model, I allow for time-dependence of these variables, which leads to satisfactory results of specification tests. ${ }^{86}$ Friedman and co-authors use two models that rely on the proportional hazard assumption: the Cox proportional hazard model and the Gompertz model (Friedman et al., 1995, 1993). I use a model that preserves the semi-parametric feature of the Cox model, while allowing for the relaxation of the proportional hazard assumption for all variables for which it doesn't hold. In addition, I use dummies for each education level thus relaxing the strong assumption of proportionality of effect of education to years of schooling relied on by Friedman et al. In this paper, I also account for latent factors and the measurement error in measures by using a one-step maximum likelihood estimation procedure. In contrast, Friedman and co-authors use equally-weighted indexes of psychological measures as regressors (Friedman et al., 1993). Thus, they fail to account for differential measurement errors in the proxies of traits. Yet, measurement error is far from equal for measures of Conscientious-

\footnotetext{
${ }^{86} \mathrm{I}$ cannot reject the proportional odds tests.
} 
ness. ${ }^{87}$ As I show in Figure 12, measurement error in measures of Conscientiousness ranges from as small as $24 \%$ (for a measure called "conscientiousness") to as large as $80 \%$ (for a measure called "freedom from vanity").

In an early paper, Friedman et al. (1993) estimate longevity models separately by gender, and find no statistically significant effect of Conscientiousness for females. In a later work, despite their early findings, Friedman et al. (1995) model longevity for a pooled sample of males and females without accounting for the potential gender difference in the effect of Conscientiousness on longevity. This model only accounts for the gender difference in the average level of mortality by allowing for a different intercept. Their results imply that there is a strong and statistically significant effect of Conscientiousness on longevity for both males and females, an effect described by the same regression coefficient. Given the wellknown gender disparities in longevity, health, and health habits (e.g., Read and Gorman (2010), I perform my analysis separately by gender. As mentioned earlier, I find strong and statistically significant effects of education, Conscientiousness, and their interaction on longevity of males, but I find no such effects for females.

Based on new exploratory factor analysis, I confirm the Conscientiousness measures used by Friedman and co-authors. I also complement results of the previous literature by finding that we can reliably control for Openness using 1922 measures, but I do not find any effect of Childhood Openness on longevity.

Throughout this paper, I use a number of findings by Friedman and co-authors when interpreting my results. Friedman et al. argue that Conscientiousness leads to better health habits (less smoking, drinking, and substance abuse), better social environments, and more stable marriages (Friedman and Martin, 2011; Goodwin and Friedman, 2006). They argue that there is a negative association between Conscientiousness and a large array of severe medical conditions including serious depressions, diabetes, tuberculosis, and stroke.

A meta-analysis by Kern and Friedman (2008) based on 20 different samples shows that

\footnotetext{
${ }^{87}$ In this paper I use the same four measures of childhood Conscientiousness as Friedman with co-authors.
} 
the link between Conscientiousness and longevity is not specific to Terman subjects. Furthermore, Martin and Friedman (2000) calculate correlations between the Big Five traits and traits based on the Terman questionnaires and show a strong relationship between them. These results allow me to relate my findings to the established Big Five taxonomy of personality traits and argue about possible generalizations of my results.

\section{Conscientiousness and Education as Substitutes for Longevity Production In}

this paper, I show empirically that Conscientiousness and education are substitutes in the production of longevity. As shown in Tables 4 and 5, the effects of Conscientiousness on longevity are only strong and statistically significant at low levels of education (high school, some college, and bachelor's degree for males; some college for females). At the same time, the effect of education on longevity has a tendency to decline with Conscientiousness, which is especially evident for the effect of obtaining a master's degree or a doctorate ${ }^{88}$ (see panels (c) and (d) in Figure 8). This strong negative interaction between Conscientiousness and education in producing longevity was previously unknown and needs explanation.

I conjecture that the interaction occurs because Conscientiousness and education affect health and longevity through many common mediators, including smoking, alcohol consumption, mental health, physical activity, patient adherence to medical protocols, and obesity. ${ }^{89}$ Given these overlapping mediators, it is possible that Conscientiousness and education crowd each other out in the production of health. High levels of Conscientiousness improve outcomes for these health mediators, thus lessening the effect of additional educational attainment (and vice versa). This intuition is in line with results by Conti et al. (2010a,c), who

\footnotetext{
${ }^{88}$ The effect is relative to the baseline category: high school graduate.

${ }^{89}$ Researchers find effects of education on the following mediators of longevity: smoking, obesity, depression, diet, alcohol consumption, physical activity, regular exercise, regular health checkups, and patient adherence to medical protocols (Conti et al., 2010a,c; Droomers et al., 1998, 1999; Hegazi et al., 2010; Park and Kang, 2008; Ross and Mirowsky, 1998, 1999; Thrane, 2006). It has also been demonstrated that Conscientiousness affects at least the following mediators: smoking, alcohol consumption, mental health, patient adherence to medical regimens for renal dialysis, vigorous physical activity, physical activity, drug use, unhealthy eating, risky driving, risky sex, suicide, and violence (Bogg and Roberts, 2004; Christensen and Smith, 1995; de Brujin et al., 2009; Friedman et al., 1995; Martin et al., 2007, 1995; Roberts and Walton, 2004).
} 
show a negative interaction between education and self-control, a trait closely related to Conscientiousness, in affecting smoking (for males and females), depression (for males), and obesity (for males).

Gender Differences It has been firmly established in the literature that women live longer than men, even though they have higher morbidity and lower socio-economic statuses. Women are more biologically robust, less exposed to risky and unhealthy behaviors, and use more preventative care, and these differences positively affect their longevity (see, for example, Read and Gorman (2010) for a survey of findings on gender differences in health and longevity).

In this paper, I find strong effects of education and Conscientiousness on the longevity of males, whereas the effects for females are not precisely determined. These gender differences have two sources, each documented in the literature: (1) differential effects of education on health mediators, and (2) differential effects of health mediators on health. Conti et al. (2010a,c) find that the causal effects of education on obesity, exercise, and employment are stronger for males than for females, thus contributing to the first source of gender differences. As mentioned above, the second source of gender differences is due to the greater biological robustness of females: longevity of females is less affected by external factors. Finally, since males are more exposed to risky and unhealthy behaviors than females (Read and Gorman, 2010), the effects of education and Conscientiousness acting through these behavioral mediators should be, on average, stronger for males. ${ }^{90}$

Data Limitations and External Validity The effects of education and Conscientiousness on the longevity of males at the top $0.4 \%$ of the cognitive distribution born at the beginning of the $20^{\text {th }}$ century are likely generalizable to males from later cohorts and with lower intelligence.

\footnotetext{
${ }^{90}$ Females born around 1910 had relatively healthy behaviors partly because of existing social conventions. We can expect that for contemporary females, who enjoy greater freedom of behavior choice, Conscientiousness and education may play stronger role in promoting health and longevity.
} 
Not much has changed in the social role of males since the beginning of the $20^{\text {th }}$ century. Later generations have increased longevity, but there is no reason to believe that the effects of education and Conscientiousness, which are primarily mediated through healthy lifestyles (Bogg and Roberts, 2004), would disappear. Moreover, contemporary cohorts have better knowledge regarding the determinants of health, especially about hazardous effects of smoking and unhealthy diet. This likely makes the effect of Conscientiousness even stronger than for Terman subjects, since conscientious people are better at resisting temptation. For instance, the Terman data shows that both child and adult Conscientiousness are inversely correlated with smoking and heavy drinking (Martin et al., 2007).

Furthermore, the results can likely be generalized to populations with lower IQs. As already mentioned, both Conscientiousness and education are known to affect health through healthy lifestyles (Bogg and Roberts, 2004; Hampson and Friedman, 2008). Unlike cognitively loaded activities such as professional chess playing, choosing a healthy lifestyle does not require an extraordinarily high cognitive ability for success. Hence, it is likely that the effects of both education and Conscientiousness on longevity are also valid also for people with somewhat lower IQs. Grossman's results, which were discussed above, suggest that IQ levels as low as the median of a cognitive score distribution of high school graduates might still have similar moderating capabilities (Grossman, 1975).

In contrast to the results for males, little can be said or generalized about females. Model estimates of the effects of education and Conscientiousness on longevity for females are, generally, not precisely determined. It is possible that the descriptive results for females, such as those in Figures 2-5, D-5-D-9, D-11 and in Tables 1-2, might be generalizable to somewhat lower IQs for the same cohort. However, the results may not be generalizable to later cohorts, since the role of females in the society, specifically in the marriage and job markets, has changed dramatically during the course of the $20^{\text {th }}$ century (Chiappori et al., 2009). 


\section{Conclusions}

In line with the emerging cognitive-noncognitive literature in economics, this paper explicitly accounts for noncognitive traits in order to investigate relationships between noncognitive traits, education, and longevity. To obtain my results, I use concepts and methods from psychometrics, a discipline at the forefront of measuring both cognitive and noncognitive traits.

I apply these tools to a widely recognized, but still largely unsolved problem in health economics: the problem of unknown confounding factors that may affect both education and health, leading to spurious correlation and false causality claims. I find a confounding factor, Conscientiousness, which has proven to be firmly linked to its well-established Big Five counterpart (Martin and Friedman, 2000), and which strongly affects both education and longevity. In addition, Conscientiousness strongly interacts with education in affecting longevity.

I find a strong causal effect of both higher education and Conscientiousness on longevity for males, and I further determine that education and Conscientiousness are substitutes for each other. The effect of Conscientiousness on longevity is only strong at low levels of education, and the effect of education on longevity is especially strong at low levels of Conscientiousness.

The causality of education on health and longevity has standard implications for positive education subsidies in cases where education investments are at sub-optimal levels. The causality of Conscientiousness, however, suggests a new dimension for economic thought and public policy: encouraging the development of child Conscientiousness at home and at school may contribute to the production of both education and longevity. Thus, the question of the malleability of Conscientiousness deserves increased research efforts. 
Figure 1: A Scheme of the Production Function for Longevity

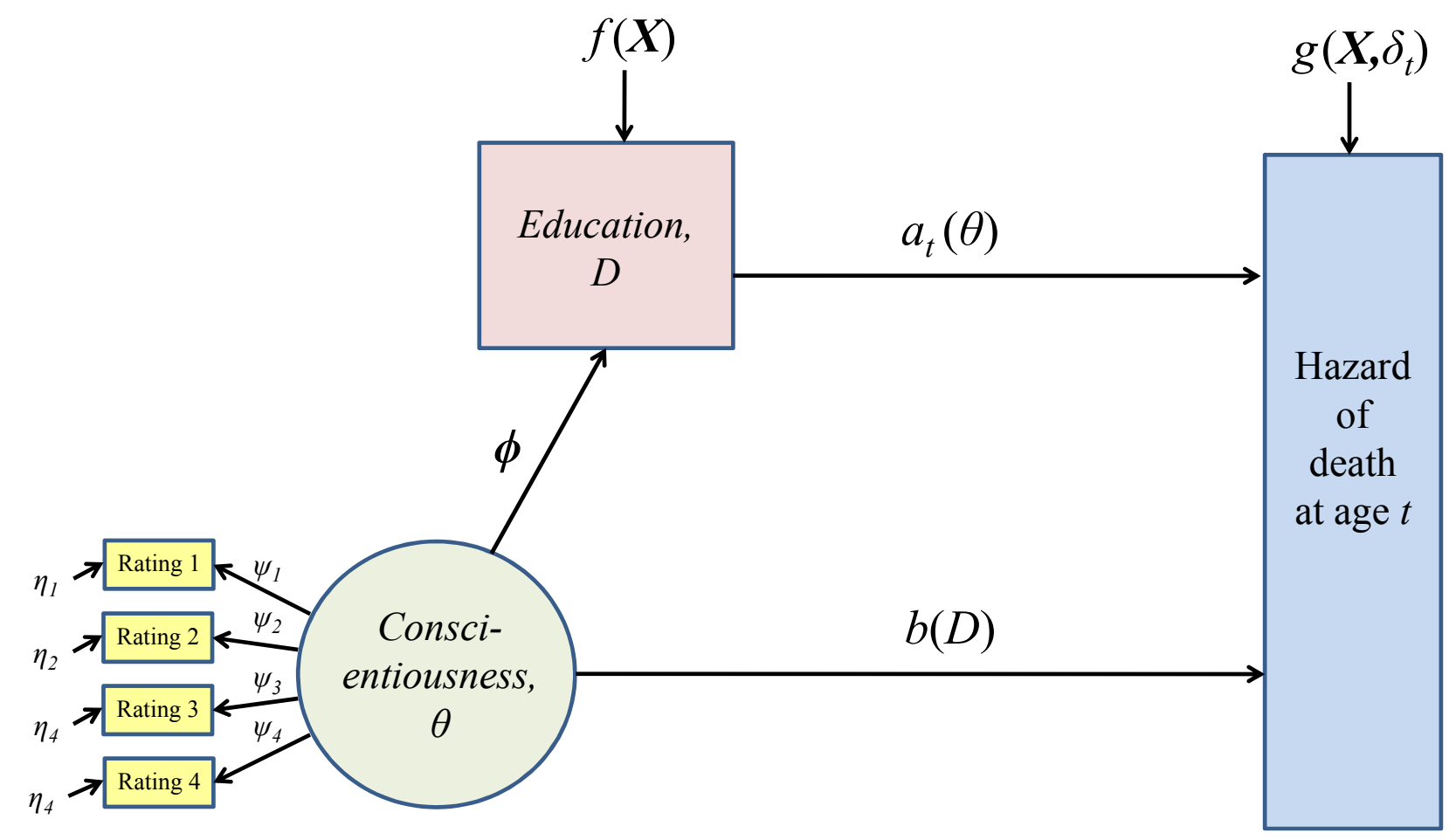

Note: This scheme is a simplified visualization of the econometric model (see equations (8), (9), (10), (16)) estimated in this paper. There are no coefficients such as $a_{t}(\theta)$ or $b(D)$ in the model.

Latent Conscientiousness $\theta$ causally affects education $D$. Education causally affects health, with the effect $a_{t}(\theta)$ depending on the level of Conscientiousness and varying by age $t$. In turn, the effect $b(D)$ of Conscientiousness on the hazard of death depends on the level of education $D$.

The three major variables of interest-Conscientiousness, education, and the hazard of death - are not only related among themselves, but are also related to other variables. Education is affected by some function of background variables, $f(\boldsymbol{X})$. Hazard of death is affected by some function $g\left(\boldsymbol{X}, \delta_{t}\right)$ of background variables $\boldsymbol{X}$ and an age-specific parameter, $\delta_{t}$. Finally, Conscientiousness affects its four ratings. Each rating is also affected by a measurement error, $\eta$. Conscientiousness has different influences on the proxies, measured by the $\psi$ 's. The $\psi$ for the first proxy is normalized to 1 in order to achieve identification. 
Figure 2: Survival Function, $S_{\tau}$, by Education

(a) Males

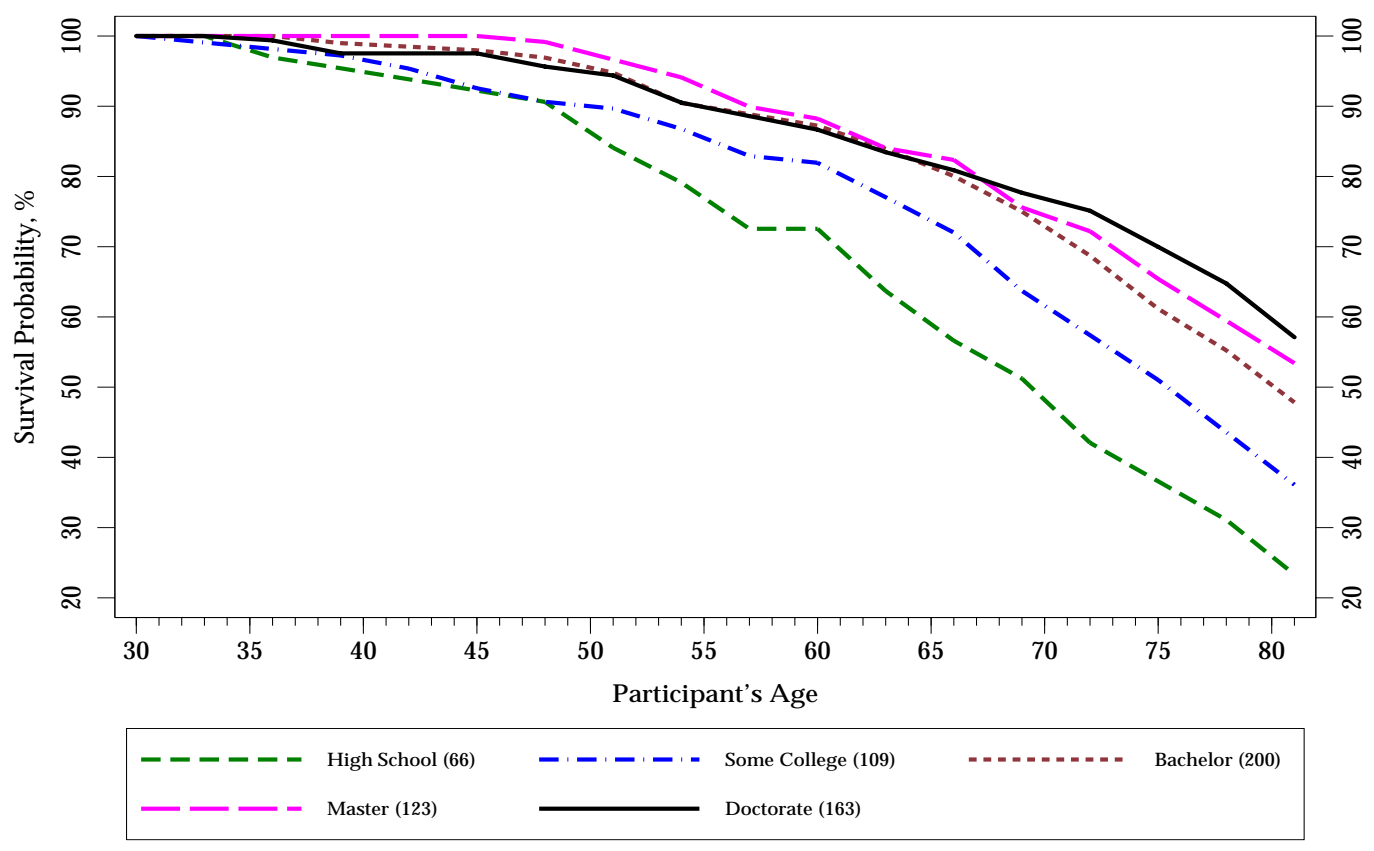

(b) Females

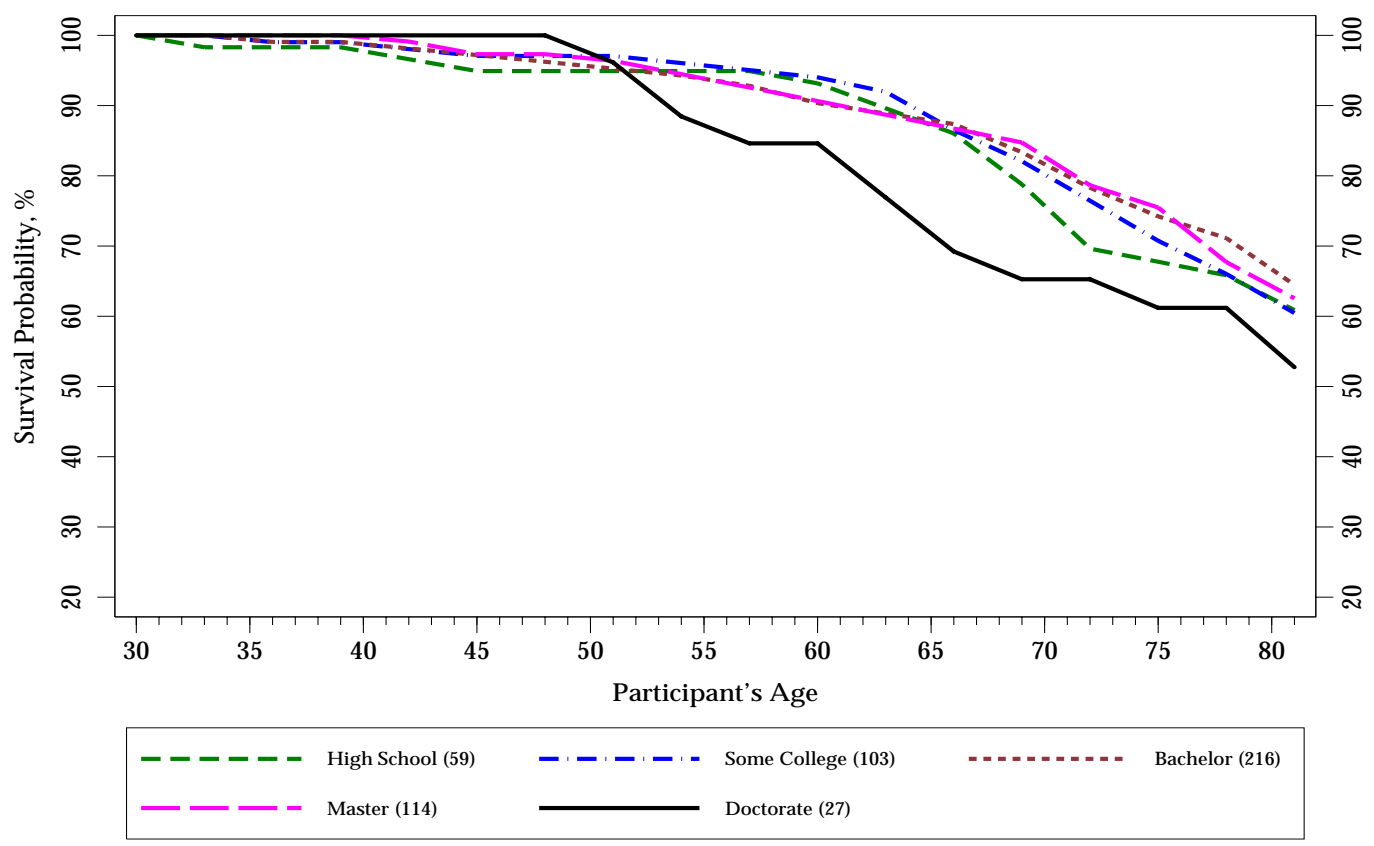

Notes: Probability of survival is conditional on survival through age 30. Sample sizes are shown in parentheses. Education groups are mutually exclusive and refer to the highest level of education obtained in life. Calculations are based on the Terman data. 

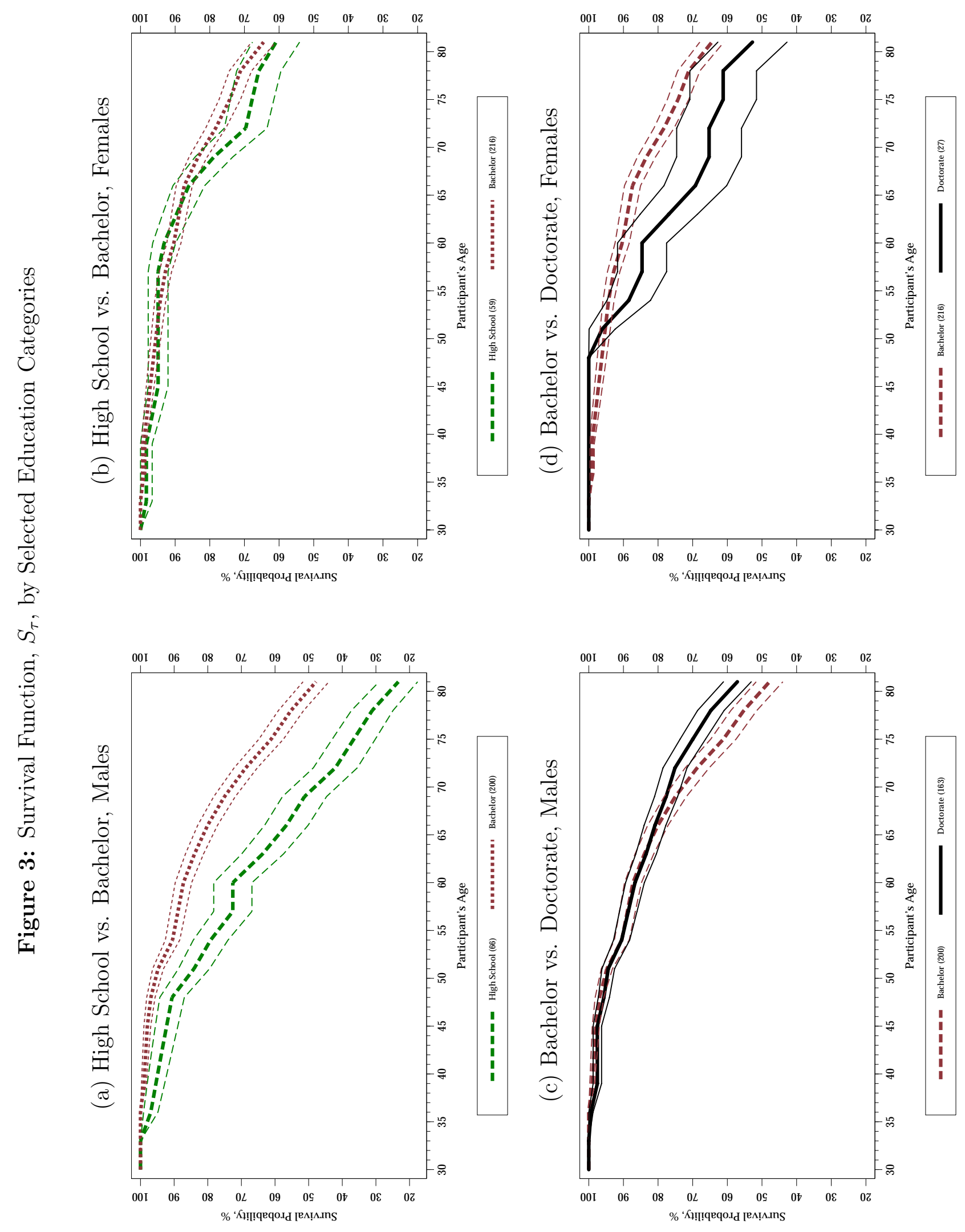

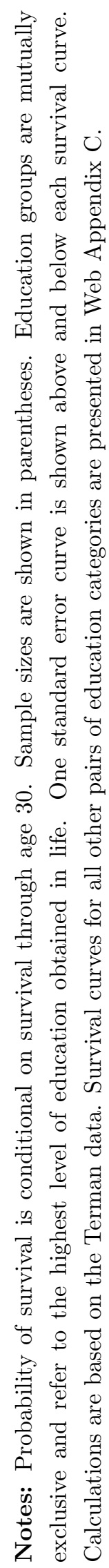




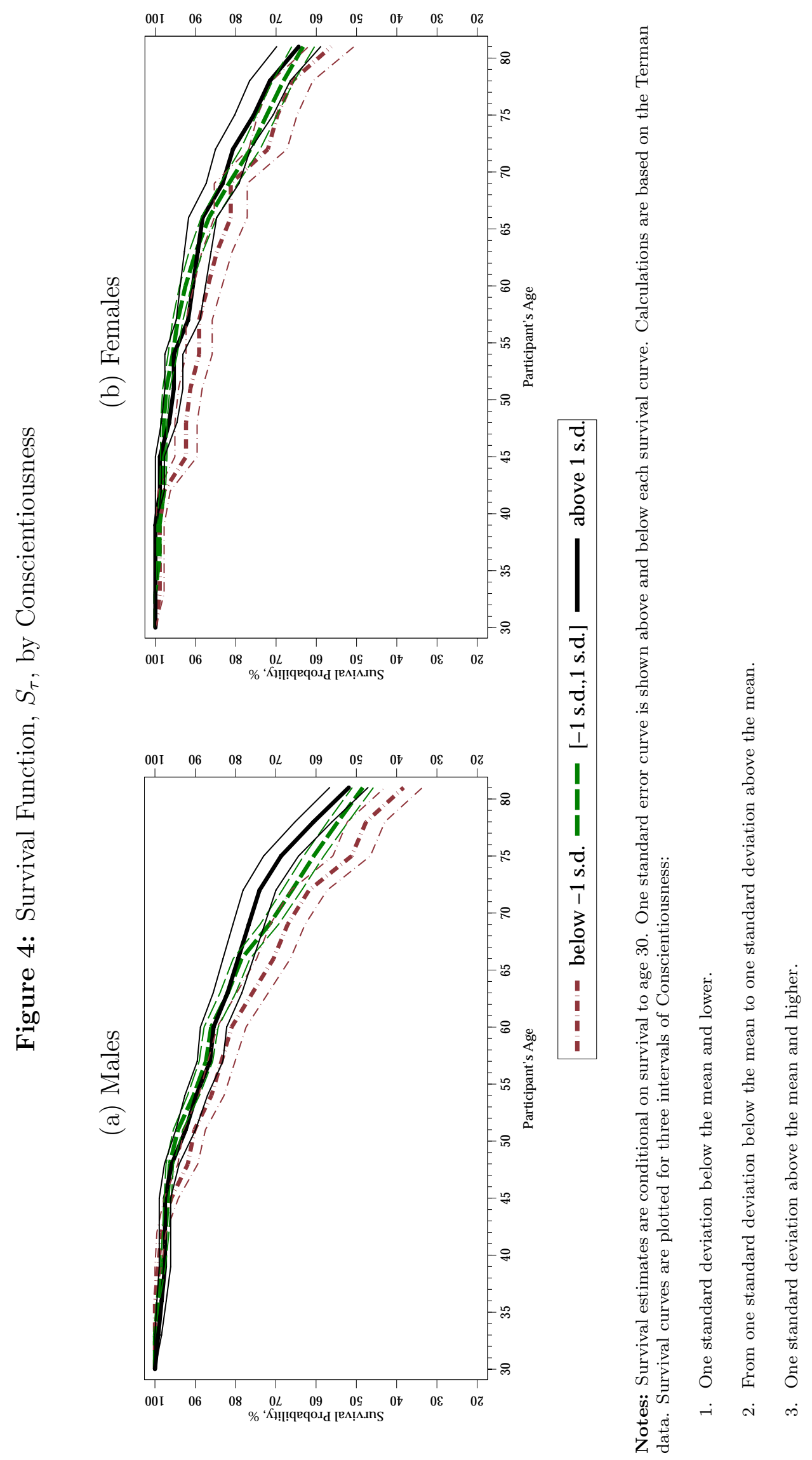




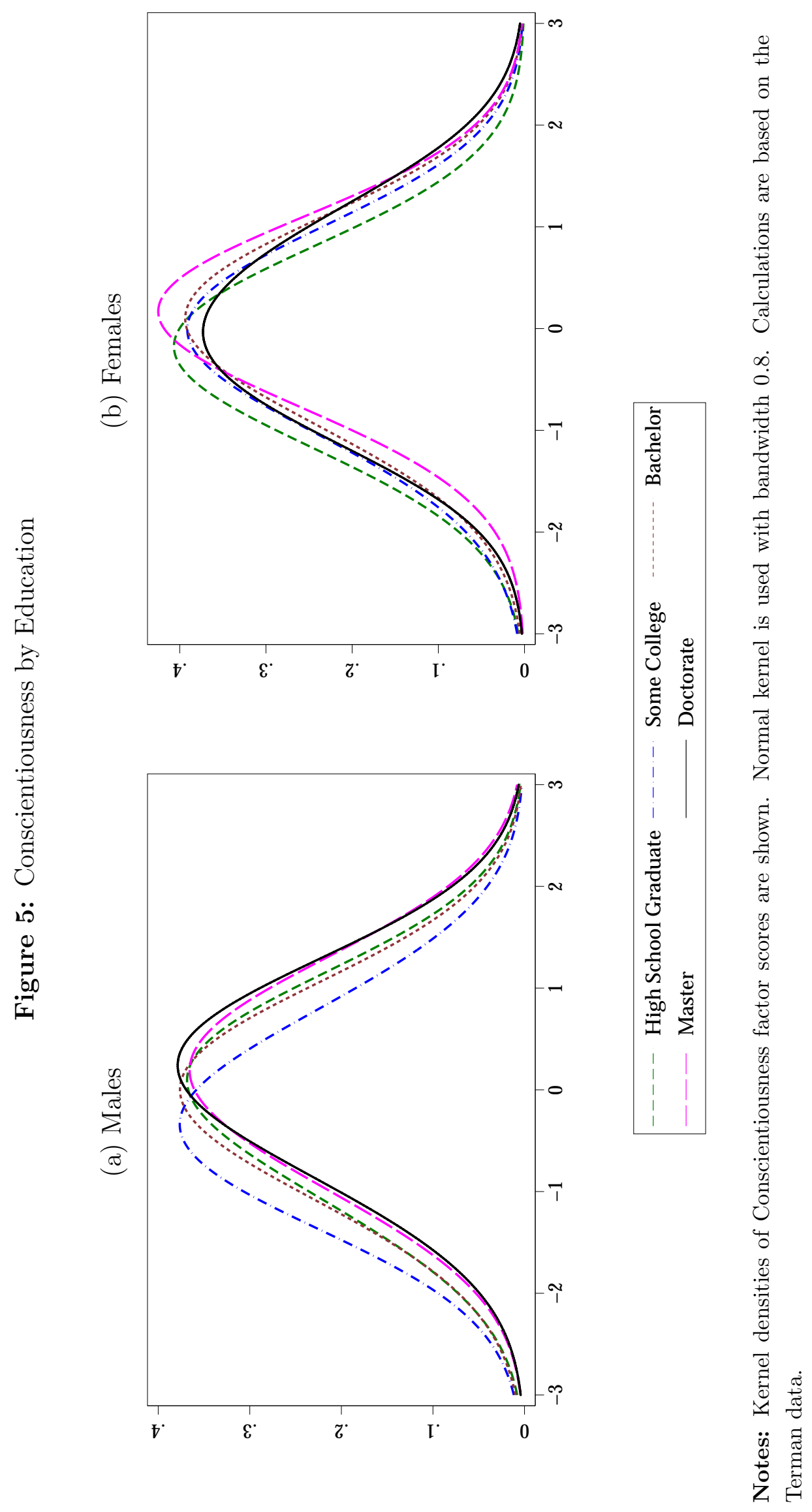




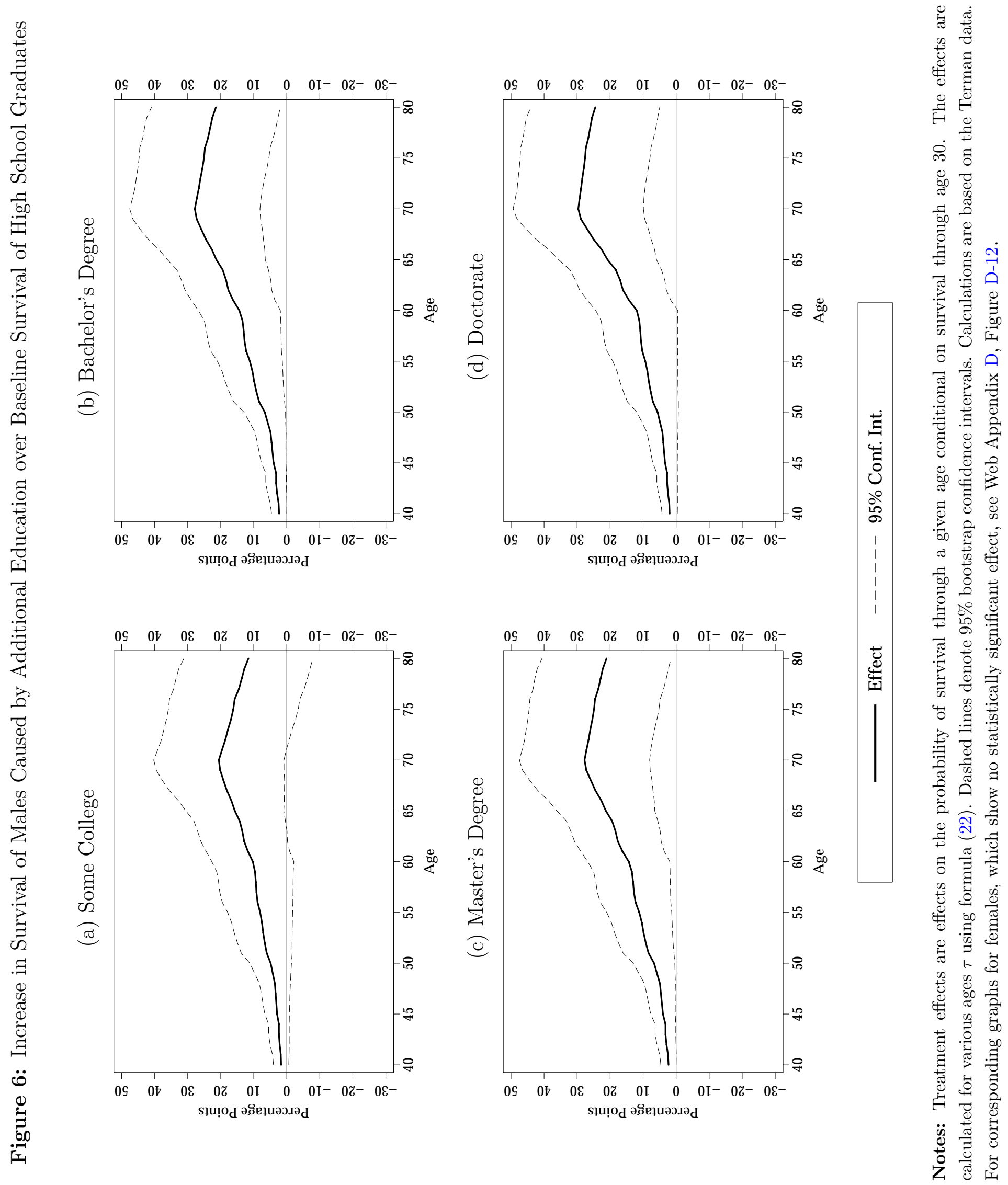




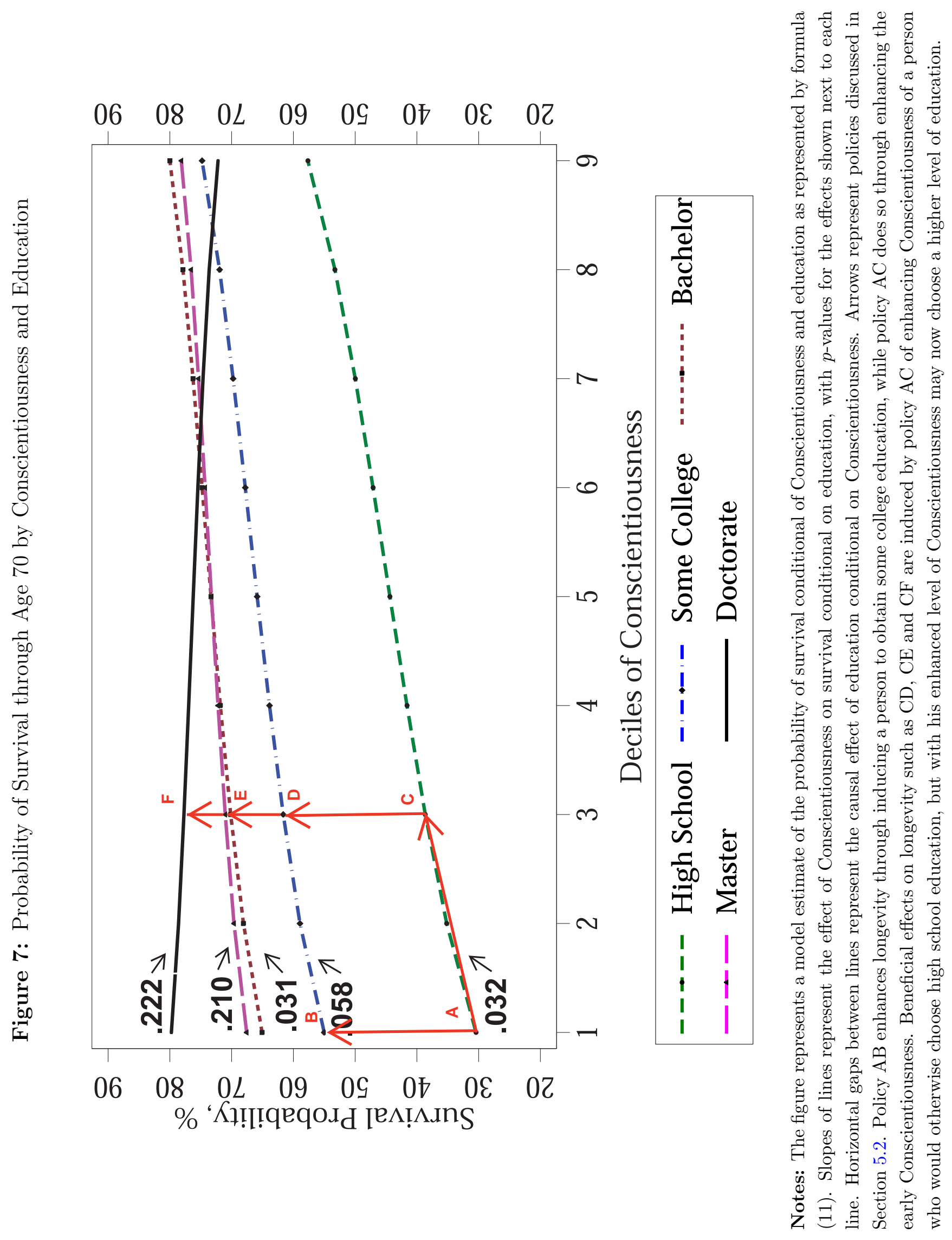




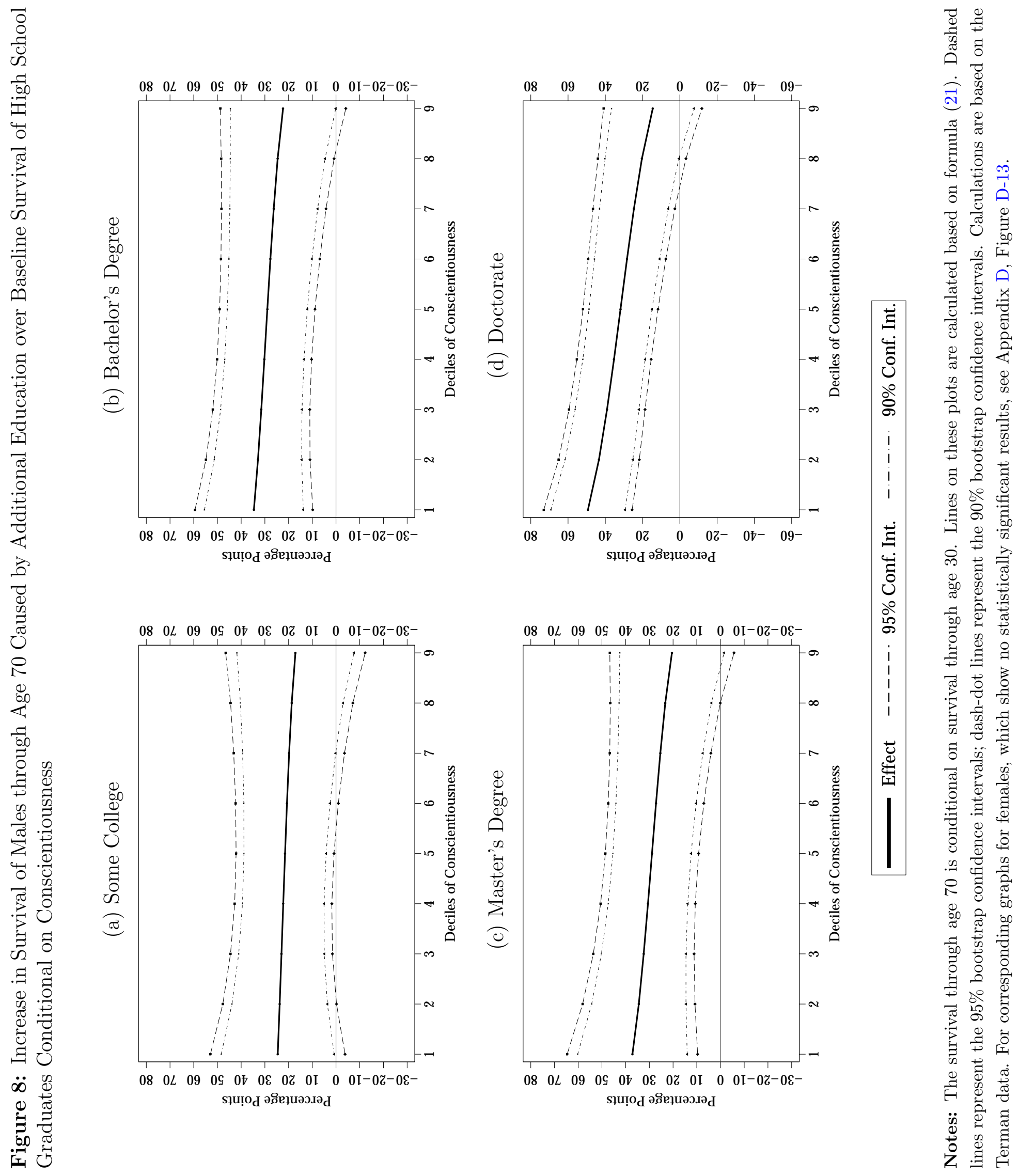


Figure 9: Direct, Indirect, and Total Effects of Conscientiousness on Survival through Age 70, Males

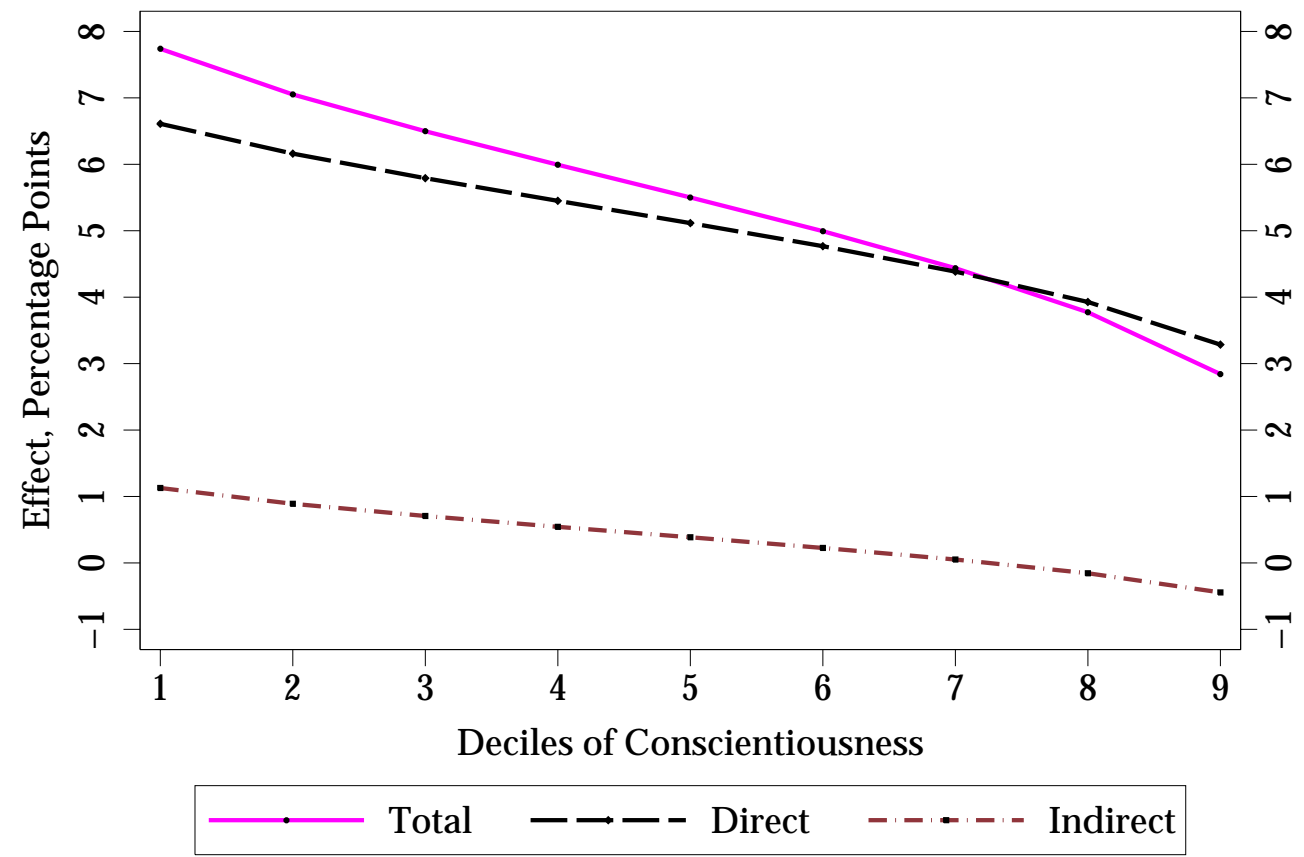

\section{Notes:}

The effect is the change in the probability of survival in response to a small change in Conscientiousness. The scale of the effect corresponds to one standard deviation change in Conscientiousness. Survival through age 70 is conditional on survival through age 30. The decomposition is calculated based on formula (27). 

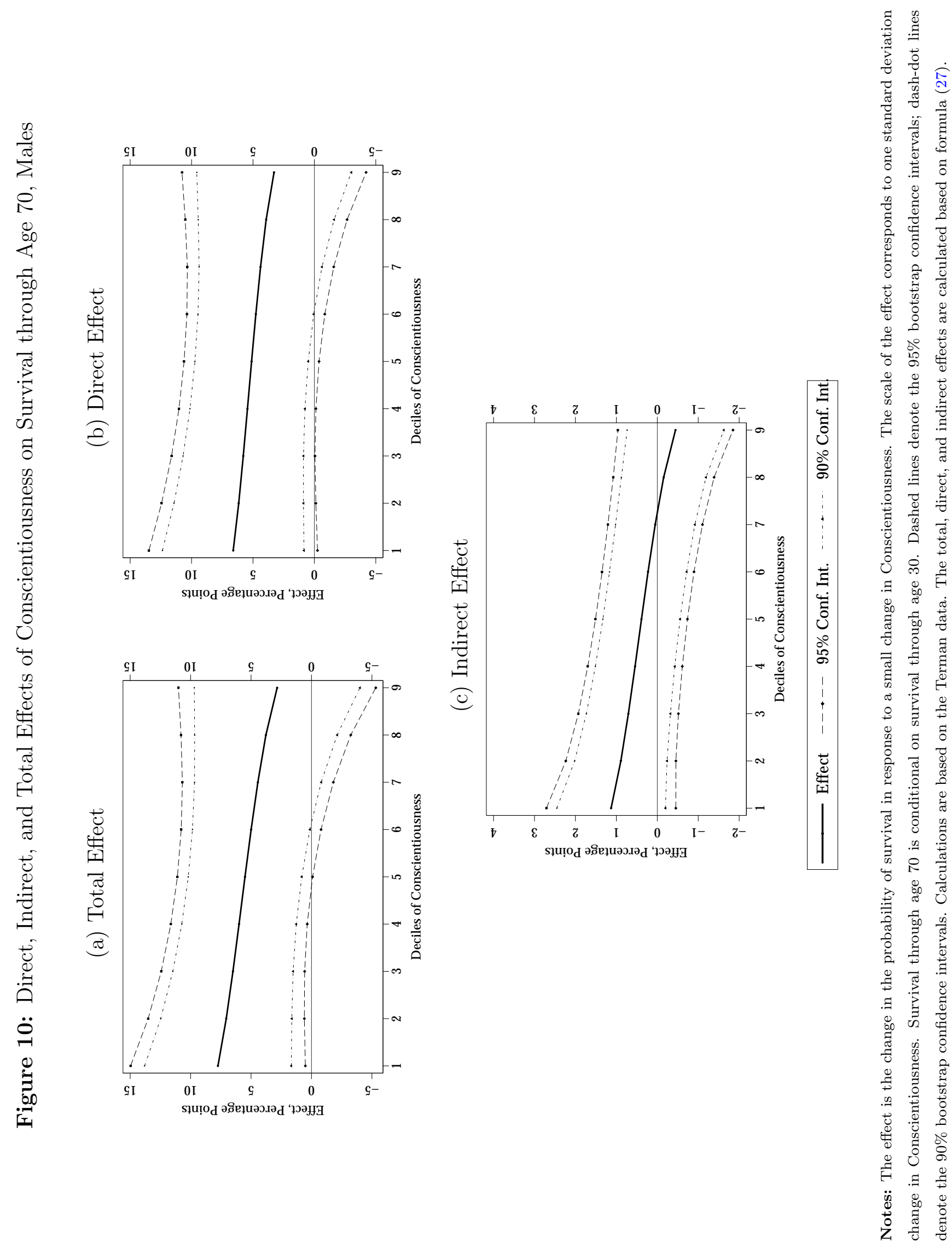


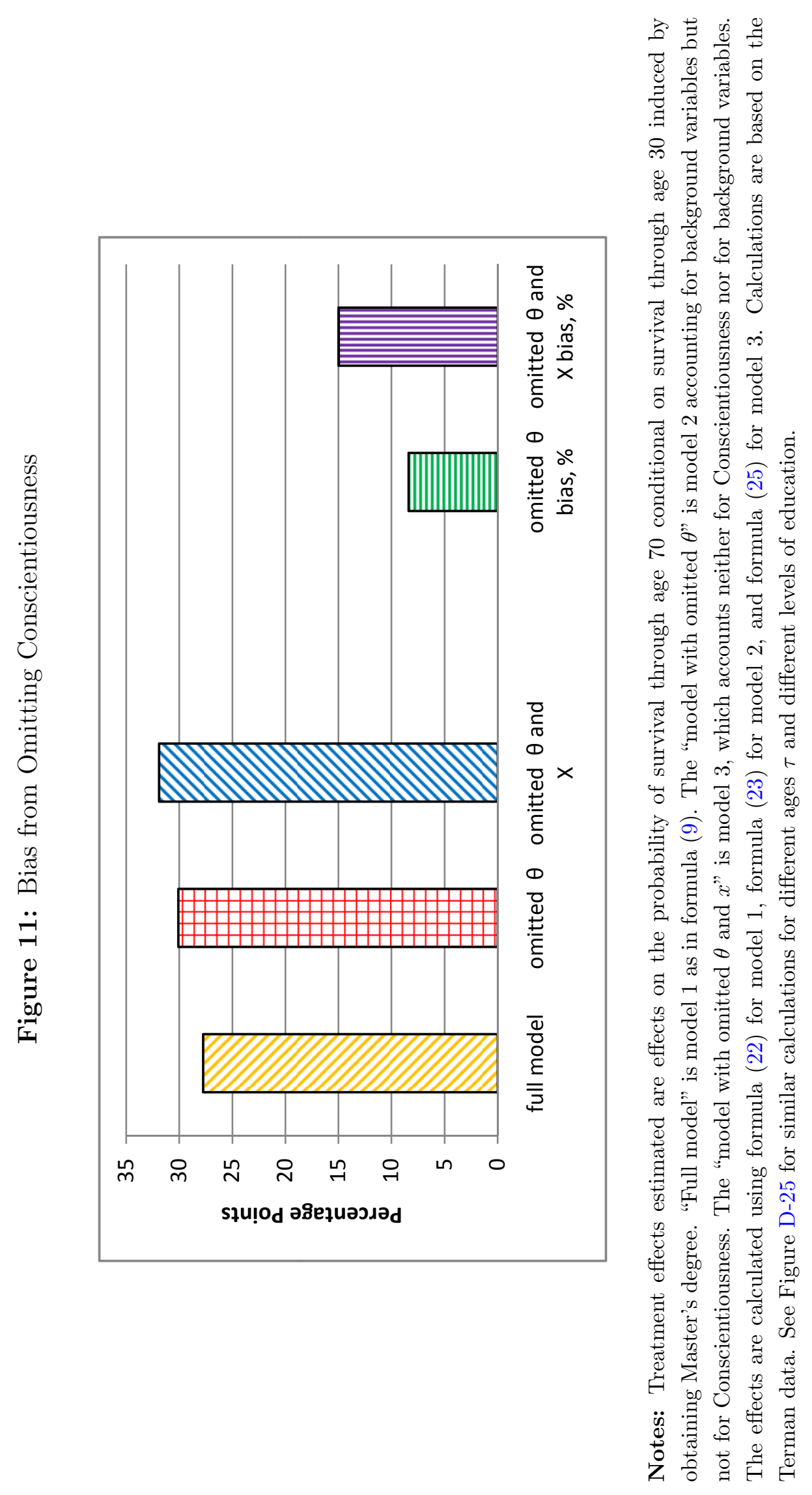




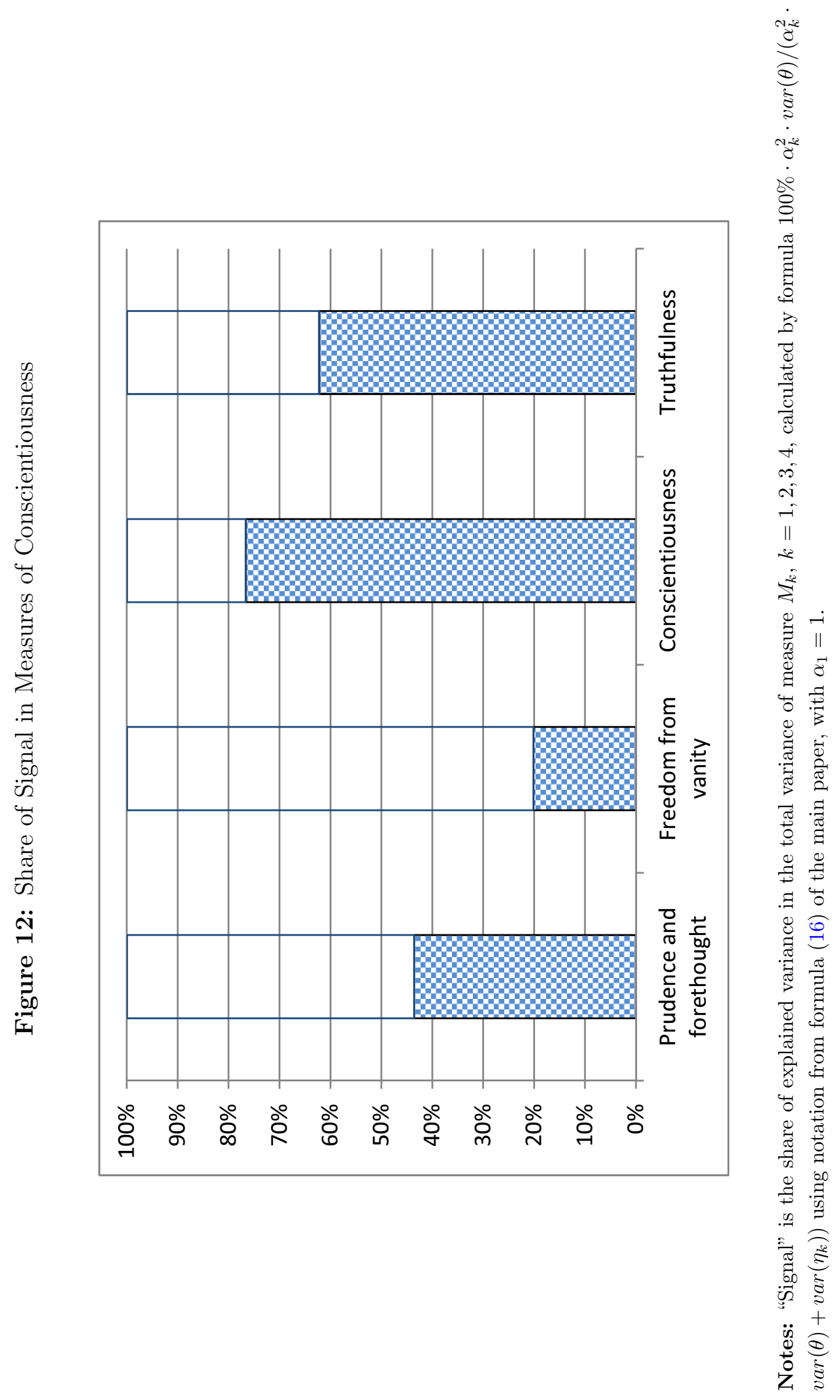




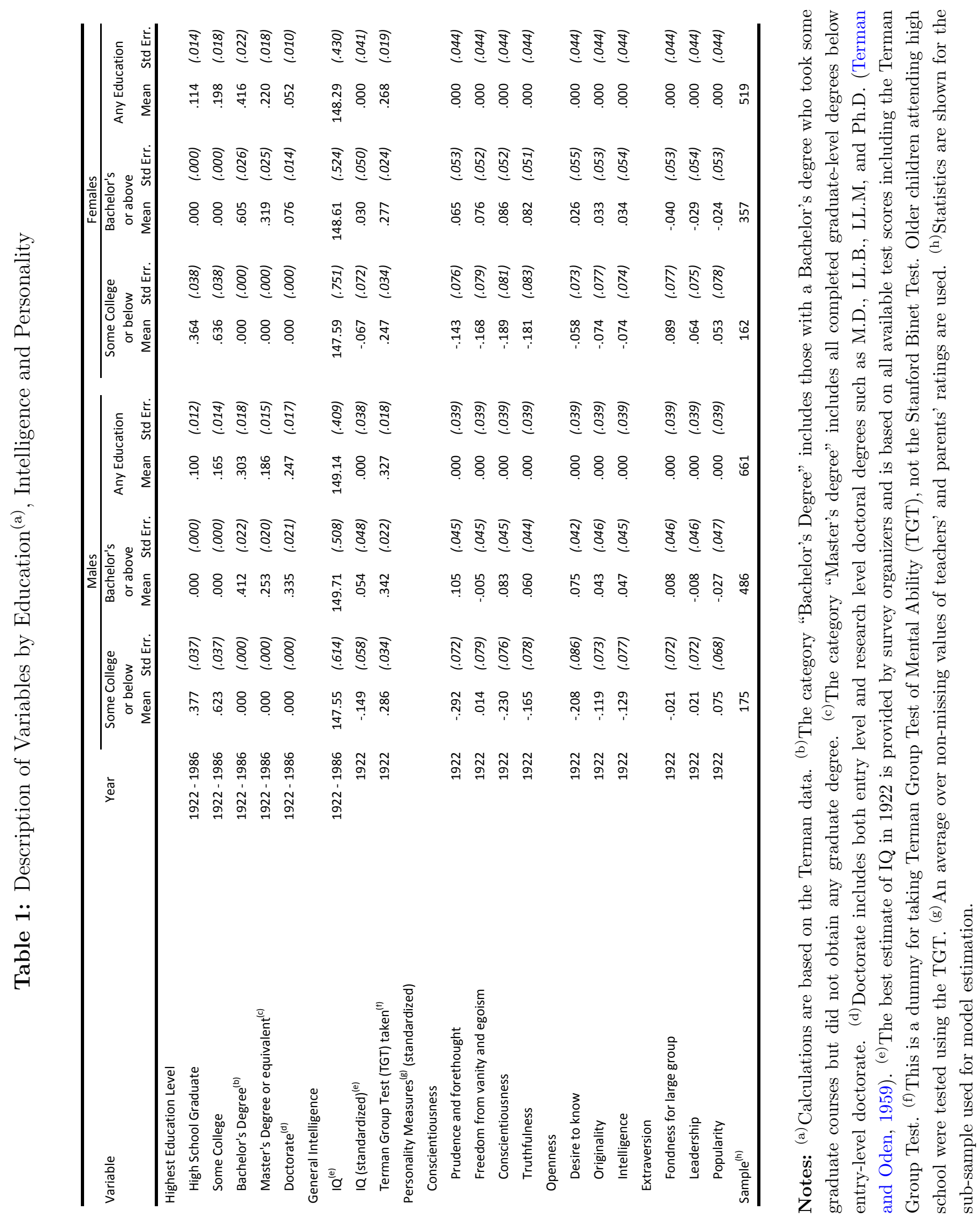




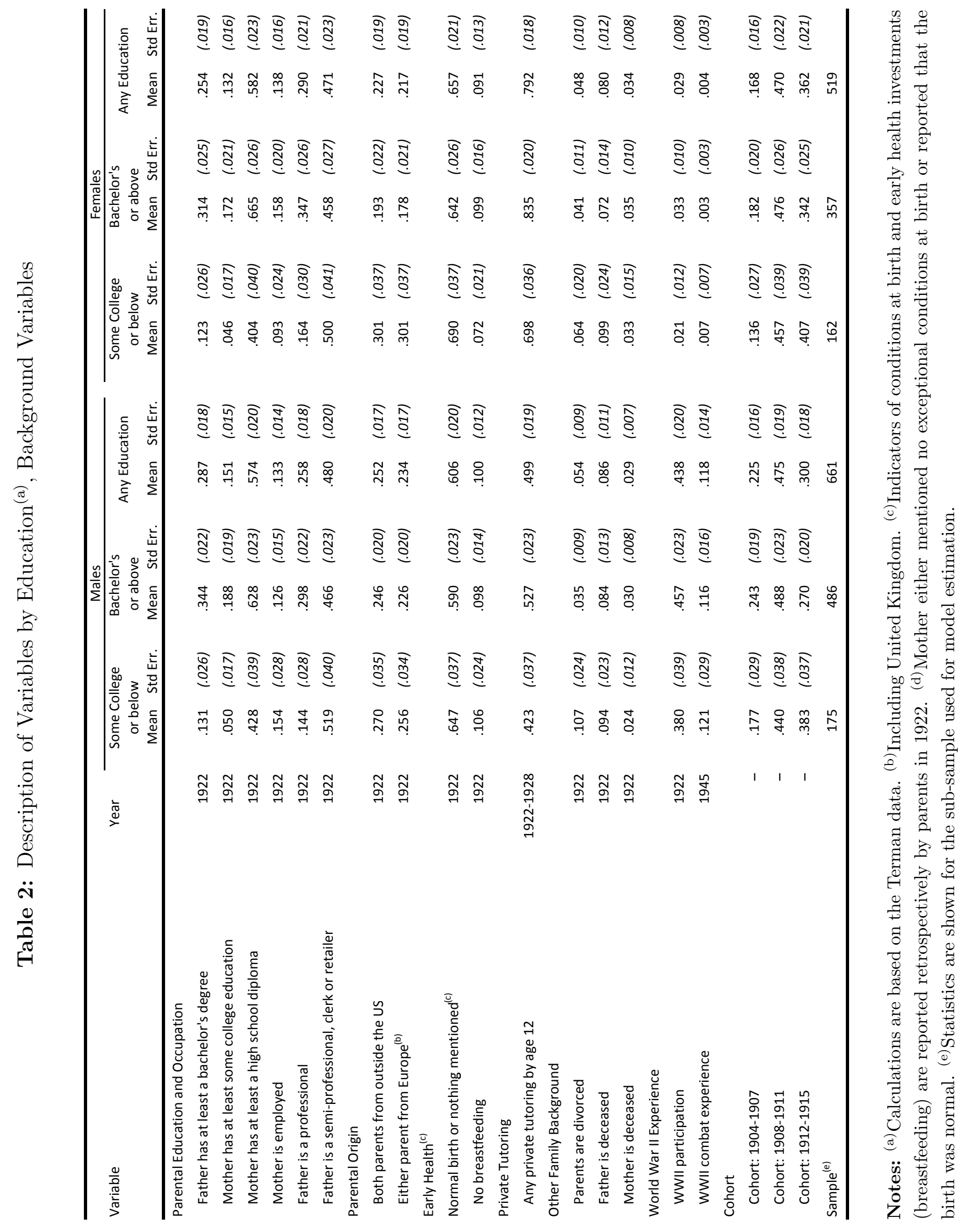


Table 3: Personality Traits and their Measures

\begin{tabular}{|c|c|c|c|}
\hline Trait & \# of Measures & Year of Measurement & 1922 Personality Measures \\
\hline \multirow[t]{4}{*}{ Conscientiousness } & 4 & 1922 & Prudence and forethought \\
\hline & & & Freedom from vanity and egoism \\
\hline & & & Conscientiousness \\
\hline & & & Truthfulness \\
\hline \multirow[t]{3}{*}{ Openness } & 3 & 1922 & Desire to know \\
\hline & & & Originality \\
\hline & & & Intelligence \\
\hline \multirow[t]{3}{*}{ Extraversion } & 3 & 1922 & Fondness of large group \\
\hline & & & Leadership \\
\hline & & & Popularity with other children \\
\hline \multirow[t]{5}{*}{ Agreeableness } & 5 & 1940 & Easy to get along \\
\hline & & & Avoids arguments \\
\hline & & & Critical \\
\hline & & & Tactful \\
\hline & & & Ignores feelings of others \\
\hline \multirow[t]{6}{*}{ Neuroticism } & 6 & 1940 & Moodiness \\
\hline & & & Sensitive feelings \\
\hline & & & Affected by praise or blame \\
\hline & & & Worries about humiliating experiences \\
\hline & & & Easily feels hurt \\
\hline & & & Burdened by remorse or regret \\
\hline
\end{tabular}

Notes: Measures are selected based on the exploratory factor analysis of the full set of year 1922 psychological measures (see Web Appendix A). See Table 1 for descriptive statistics of these measures and Table A-7 of the Web Appendix for the internal consistency reliability estimates. See a companion paper by Gensowski, Heckman, and Savelyev (2011) for a discussion of 1940 measures. 


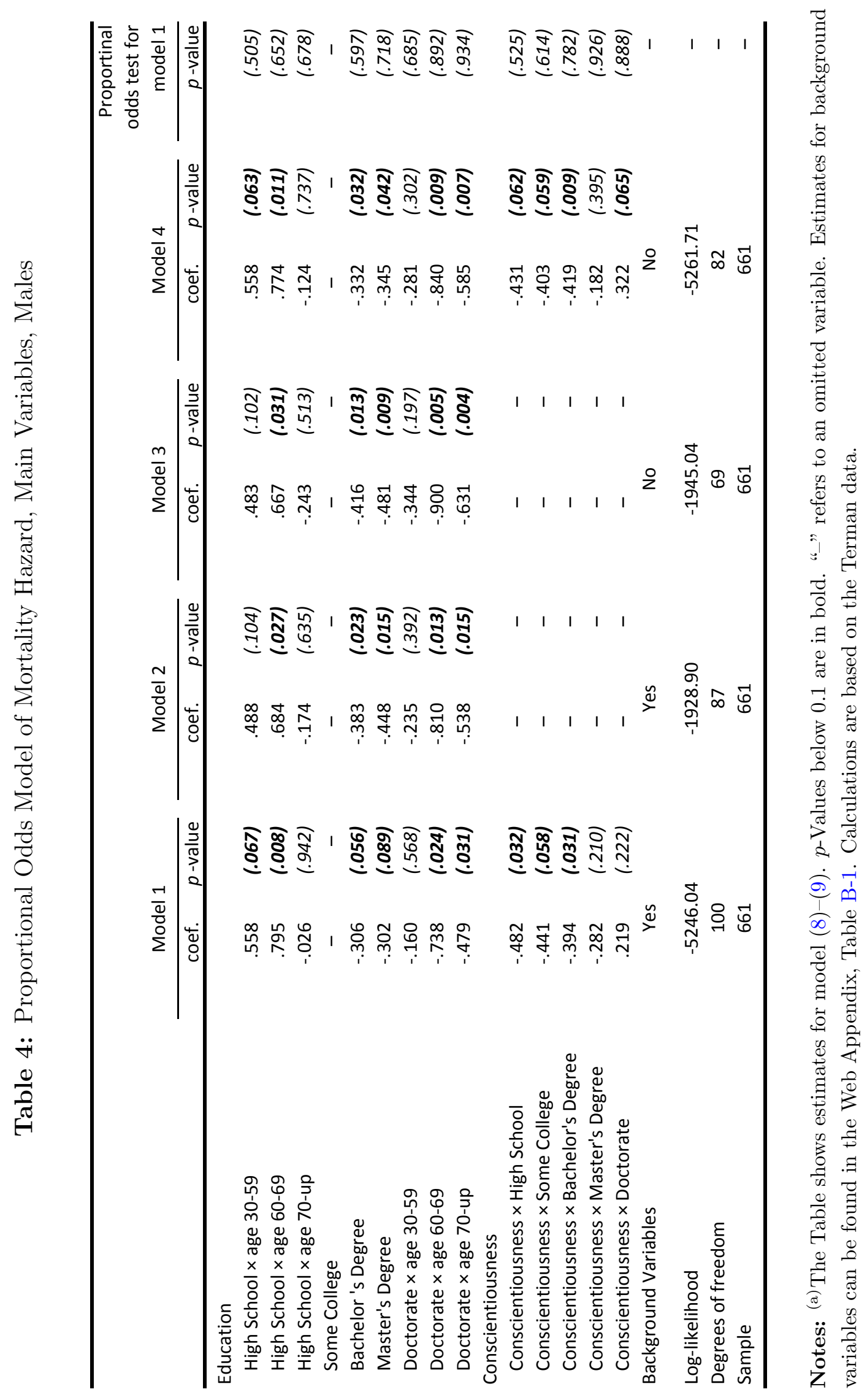




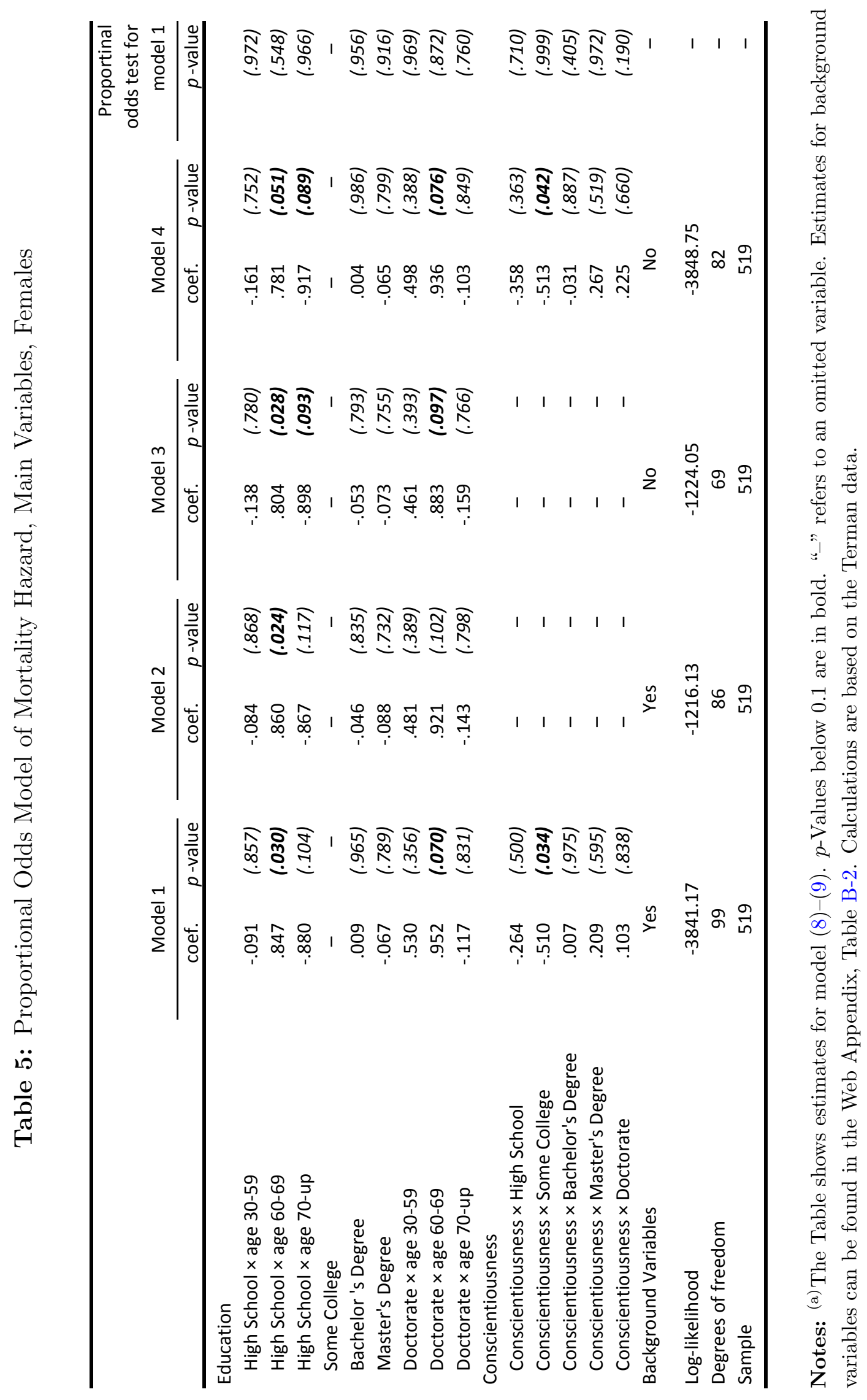




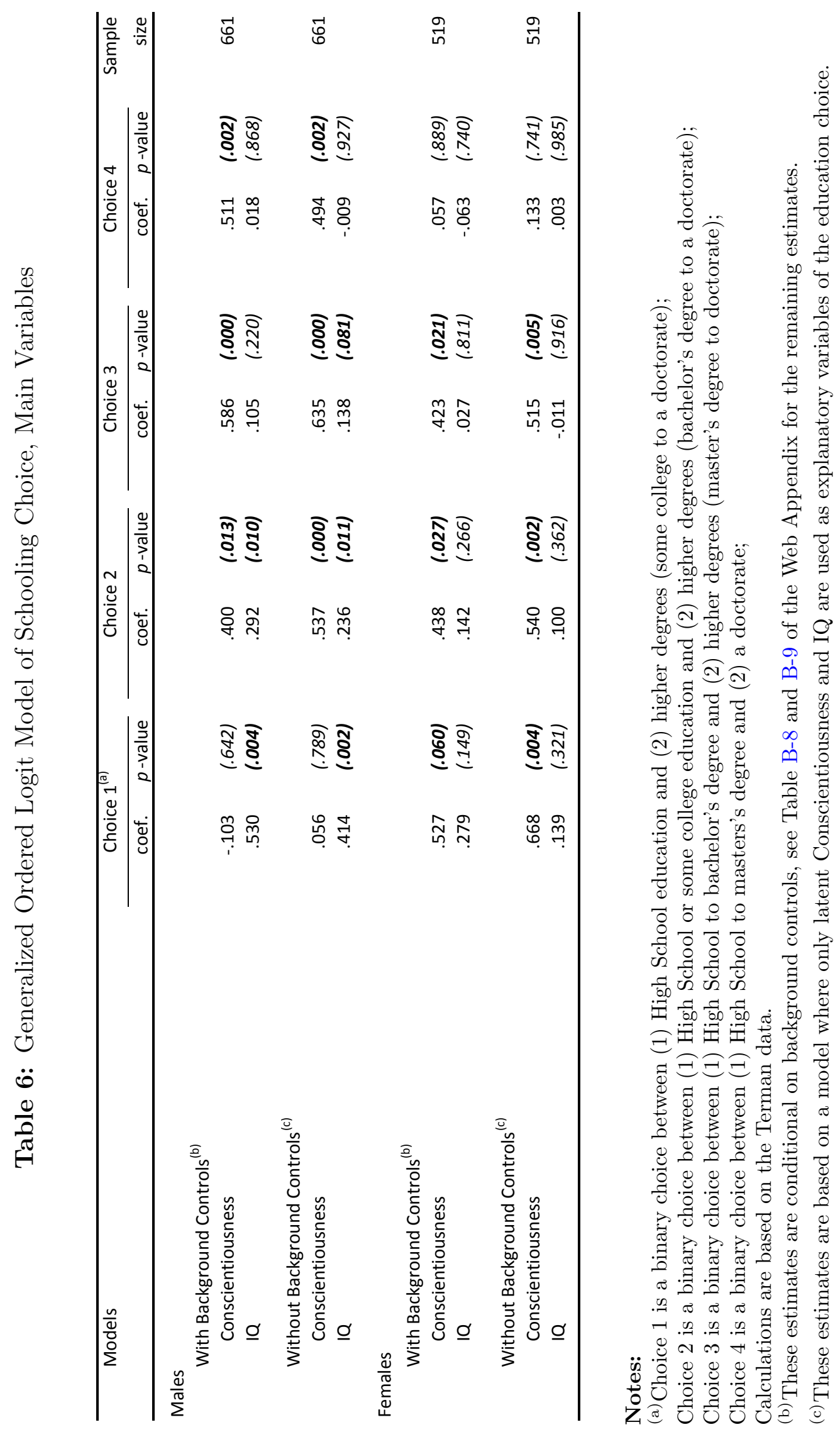




\section{References}

Ackerman, P. L. and E. D. Heggestad (1997). Intelligence, personality, and interests: Evidence for overlapping traits. Psychological Bulletin 121(2), 219-245.

Adams, S. J. (2002). Educational attainment and health: Evidence from a sample of older adults. Education Economics 10(1), 97-109.

Allen, M. J. and W. M. Yen (2002). Introduction to Measurement Theory. Prospect Heights, IL: Waveland Press.

Almlund, M., A. L. Duckworth, J. Heckman, and T. Kautz (2010). Personality psychology and economics. Unpublished manuscript, University of Chicago, Department of Economics.

Arendt, J. N. (2005). Does education cause better health? A panel data analysis using school reforms for identification. Economics of Education Review 24(2), 149-160.

Arendt, J. N. (2008). In sickness and in health - till education do us part: Education effects on hospitalization. Economics of Education Review 27, 161-172.

Auld, M. C. and N. Sidhu (2005, October). Schooling, cognitive ability and health. Health Economics 14(10), 1019-1034.

Becker, G., E. Landes, and R. Michael (1977). An economic analysis of marital instability. Journal of Political Economy 85(6), 1141-1187.

Becker, G. S. (2007, July). Health as human capital: synthesis and extensions. Oxford Economic Papers 59(3), 379-410.

Becker, G. S. and C. B. Mulligan (1997, August). The endogenous determination of time preference. Quarterly Journal of Economics 112(3), 729-58.

Bogg, T. and B. W. Roberts (2004, November). Conscientiousness and health-related behaviors: A meta-analysis of the leading behavioral contributors to mortality. Psychological Bulletin 130(6), 887-919.

Bollen, K. A. (1989). Structural Equations with Latent Variables. New York: Wiley.

Borghans, L., A. L. Duckworth, J. J. Heckman, and B. ter Weel (2008, Fall). The economics and psychology of personality traits. Journal of Human Resources 43(4), 972-1059.

Borghans, L., B. H. H. Golsteyn, J. J. Heckman, and J. E. Humphries (2011). IQ, achievement, and personality. Unpublished manuscript, University of Maastricht and University of Chicago (revised from the 2009 version).

Brant, R. (1990). Assessing proportionality in the proportional odds model for ordinal logistic regression. Biometrics 46, 1171-1178. 
Burks, B. S., D. W. Jensen, L. M. Terman, A. M. Leahy, H. Marshall, and M. H. Oden (1930). Genetic Studies of Genius: The Promise of Youth: Follow-Up Studies of a Thousand Gifted Children, Volume 3. Stanford University, CA: Stanford University Press.

Carneiro, P., K. Hansen, and J. J. Heckman (2003, May). Estimating distributions of treatment effects with an application to the returns to schooling and measurement of the effects of uncertainty on college choice. International Economic Review 44 (2), 361-422.

Chiappori, P.-A., M. Iyigun, and Y. Weiss (2009, December). Investment in schooling and the marriage market. The American Economic Review 99(5), 1689-1713.

Christensen, A. J. and T. W. Smith (1995). Personality and patient adherence: Correlates of the five factor model in renal dialysis. Journal of Behavioral Medicine 18.

Conti, G., J. J. Heckman, H. F. Lopes, and R. Piatek (2011). Constructing economically justified aggregates: An application to the early origins of health. Under revision, Journal of Econometrics.

Conti, G., J. J. Heckman, H. F. Lopes, and R. Pinto (2009). Towards greater understanding of early-adult risky behaviors: Cognitive ability, personality, and schooling effects. Unpublished manuscript, University of Chicago, Department of Economics.

Conti, G., J. J. Heckman, and S. Urzua (2010a). Early endowments, education, and health. Unpublished manuscript, University of Chicago, Department of Economics.

Conti, G., J. J. Heckman, and S. Urzua (2010b). The early origins of the education-health gradient. Under revision, Perspectives on Psychological Science.

Conti, G., J. J. Heckman, and S. Urzua (2010c, May). The education-health gradient. American Economic Review: Papers and Proceedings 100(2), 1-5.

Cox, D. R. (1972). Regression models and life-tables. Journal of the Royal Statistical Society 34, 187-220.

Cunha, F. and J. J. Heckman (2007, May). The technology of skill formation. American Economic Review 97(2), 31-47.

Cunha, F. and J. J. Heckman (2009, April). The economics and psychology of inequality and human development. Journal of the European Economic Association 7(2-3), 320-364. Presented as the Marshall Lecture, European Economics Association, Milan, Italy, August 29, 2008.

Cunha, F., J. J. Heckman, L. J. Lochner, and D. V. Masterov (2006). Interpreting the evidence on life cycle skill formation. In E. A. Hanushek and F. Welch (Eds.), Handbook of the Economics of Education, Chapter 12, pp. 697-812. Amsterdam: North-Holland.

Cunha, F., J. J. Heckman, and S. M. Schennach (2010, May). Estimating the technology of cognitive and noncognitive skill formation. Econometrica 78(3), 883-931. 
Cutler, D. M. and A. Lleras-Muney (2010, January). Understanding differences in health behaviors by education. Journal of Health Economics 29(1), 1-28.

Daly, M., L. Delaney, and C. Harmon (2009). Psychological and biological foundations of time preferences. Journal of the European Economic Association 7(2-3), 659-669.

de Brujin, G.-J., R. de Groot, B. van den Putte, and R. E. Rhodes (2009). Conscientiousness, extraversion, and action control: Comparing moderate and vigorous physical activity. Journal of Sport and Exercise Psychology 31, 724-742.

DeYoung, C. G., J. B. Peterson, and D. M. Higgins (2005). Sources of openness/intellect: Cognitive and neuropsychological correlates of the fifth factor of personality. Journal of Personality and Individual Differences 73(4), 825-858.

Droomers, M., C. T. M. Schrijvers, K. Stronks, D. van de Mheen, and J. P. Mackenbach (1998). Educational differences in leisure-time physical inactivity: A descriptive and explanatory study. Social Science and Medicine 47, 1665-1676.

Droomers, M., C. T. M. Schrijvers, K. Stronks, D. van de Mheen, and J. P. Mackenbach (1999). Educational differences in excessive alcohol consumption: The role of psychosocial and material stressors. American Journal of Preventive Medicine 29, 1-10.

Farrell, P. and V. R. Fuchs (1982, December). Schooling and health: The cigarette connection. Journal of Health Economics 1(3), 217-230.

Farsides, T. and R. Woodfield (2003). Individual differences and undergraduate academic success: the roles of personality, intelligence, and application. Personality and Individual Differences 34, 1225-1243.

Forgatch, M. S. and D. S. DeGarmo (1999). Parenting through change: An effective prevention program for single mothers. Journal of Consulting and Clinical Psychology 67(5), $711-724$.

Friedman, H. S. (2000). Long-term relations of personality and health: Dynamism, mechanisms, tropisms. Journal of Personality 68(6), 1089-1107.

Friedman, H. S. (2008, July). The multiple linkages of personality and disease. Brain, Behavior, and Immunity 22(5), 668-675.

Friedman, H. S., P. H. Hawley, and J. S. Tucker (1994). Personality, health, and longevity. Current Directions in Psychological Science 3(2), 37-41.

Friedman, H. S. and L. R. Martin (2011). The Longevity Project (first edition ed.). United States of America: Hudson Street Press.

Friedman, H. S., J. S. Tucker, J. E. Schwartz, L. R. Martin, C. Tomlinson-Keasey, D. L. Wingard, and M. H. Criqui (1995). Childhood conscientiousness and longevity: Health behaviors and cause of death. Journal of Personality and Social Psychology 68(4), 696703. 
Friedman, H. S., J. S. Tucker, C. Tomlinson-Keasey, J. E. Schwartz, D. L. Wingard, and M. H. Criqui (1993). Does childhood personality predict longevity? Journal of Personality and Social Psychology 65(1), 176-185.

Fuchs, V. R. (1982). Time preference and health: An exploratory study. In V. R. Fuchs (Ed.), Economic Aspects of Health, pp. 93-120. Chicago, IL: University of Chicago Press.

Fuchs, V. R., A. B. Krueger, and J. M. Poterba (1998, September). Economists' views about parameters, values, and policies: Survey results in labor and public economics. Journal of Economic Literature 36(3), 1387-1425.

Gensowski, M., J. J. Heckman, and P. Savelyev (2011). The rate of return to education, based on a complete work and marriage history of high-ability individuals. Unpublished manuscript, University of Chicago, Department of Economics.

Goodwin, R. D. and H. S. Friedman (2006). Health status and the five-factor personality traits in a nationally representative sample. Journal of Health Psychology 11(5), 643-654.

Grossman, M. (1972, March-April). On the concept of health capital and the demand for health. Journal of Political Economy 80(2), 223-255.

Grossman, M. (1975). The correlation between health and schooling. In N. E. Terleckyj (Ed.), Household Production and Consumption, pp. 147-211. New York: Columbia University Press.

Grossman, M. (2000). The human capital model. In A. J. Culyer and J. P. Newhouse (Eds.), Handbook of Health Economics, Volume 1, pp. 347-408. Amsterdam: Elsevier.

Grossman, M. (2006). Education and nonmarket outcomes. In E. Hanushek and F. Welch (Eds.), Handbook of the Economics of Education, Volume 1, Chapter 10, pp. 577-633. Amsterdam: Elsevier.

Grossman, M. and R. Kaestner (1997). Effects of education on health. In J. R. Behrman and N. Stacey (Eds.), The Social Benefits of Education, pp. 69-124. Ann Arbor, MI: University of Michigan Press.

Hamermesh, D. S. (1984). Life-cycle effects on consumption and retirement. Journal of Labor Economics 2(3), 353-370.

Hampson, S. and H. S. Friedman (2008). Personality and health: A life span perspective. In O. P. John, R. W. Robins, and L. Pervin (Eds.), The Handbook of Personality. New York, NY: Guilford Press.

Heckman, J. J., L. Malofeeva, R. Pinto, and P. A. Savelyev (2011). Understanding the mechanisms through which an influential early childhood program boosted adult outcomes. Unpublished manuscript, University of Chicago, Department of Economics (first draft, 2008). Under revision, American Economic Review. 
Heckman, J. J., J. Stixrud, and S. Urzua (2006, July). The effects of cognitive and noncognitive abilities on labor market outcomes and social behavior. Journal of Labor Economics $24(3), 411-482$.

Heckman, J. J., J. L. Tobias, and E. J. Vytlacil (2001, October). Four parameters of interest in the evaluation of social programs. Southern Economic Journal 68(2), 210-223.

Heckman, J. J., J. L. Tobias, and E. J. Vytlacil (2003, August). Simple estimators for treatment parameters in a latent variable framework. Review of Economics and Statistics 85 (3), $748-754$.

Heckman, J. J. and E. J. Vytlacil (2007). Econometric evaluation of social programs, part I: Causal models, structural models and econometric policy evaluation. In J. Heckman and E. Leamer (Eds.), Handbook of Econometrics, Volume 6B, pp. 4779-4874. Amsterdam: Elsevier.

Hegazi, A., R. L. Bailey, B. Ahadzie, K. Peterson, and A. Alabi (2010). Literacy, education and adherence to antiretroviral therapy in the gambia. Aids Care 22, 1340-1345.

Helson, R., V. S. Kwan, O. P. John, and C. Jones (2002). The growing evidence for personality change in adulthood: Findings frmo research with personality inventories. Journal of Research in Personality 36, 287-306.

John, O. P. and S. Srivastava (1999). The big five trait taxonomy: History, measurement and theoretical perspectives. In L. A. Pervin and O. P. John (Eds.), Handbook of Personality: Theory and Research, Chapter 4, pp. 102-138. New York: The Guilford Press.

Kaestner, R. (2009). Adolescent cognitive and non-cognitive correlates of adult health. Technical report, National Bureau of Economic Research.

Kern, M. L. and H. S. Friedman (2008). Do conscientious individuals live longer? a quantitative review. Health Psychology 27(5), 505-512.

Leibowitz, A. (1974, March/April). Home investments in children. Journal of Political Economy 82(2), S111-S131.

Lippa, R. A., L. R. Martin, and H. S. Friedman (2000). Gender-related individual differences and mortality in the Terman longitudinal study: Is masculinity hazardous to your health? Personality and Social Psychology Bulletin 26(12), 1560-1570.

Lleras-Muney, A. (2005). The relationship between education and adult mortality in the United States. Review of Economic Studies 72(1), 189-221.

Martin, L. R. and H. S. Friedman (2000). Comparing personality scales across time: An illustrative study of validity and consistency in life-span archival data. Journal of Personality 68(1), 85-110.

Martin, L. R., H. S. Friedman, and J. E. Schwartz (2007). Personality and mortality risk across the life span: The importance of conscientiousness as a biopsychosocial attribute. Health Psychology 26(4), 428-436. 
Martin, L. R., H. S. Friedman, J. S. Tucker, J. E. Schwartz, M. H. Criqui, D. L. Wingard, and C. Tomlinson-Keasey (1995). An archival prospective study of mental health and longevity. Health Psychology 14, 381-387.

Martin, L. R., H. S. Friedman, J. S. Tucker, C. Tomlinson-Keasey, M. H. Criqui, and J. E. Schwartz (2002). A life course perspective on childhood cheerfulness and its relation to mortality risk. Personality and Social Psychology Bulletin 28(9), 1155-1165.

Mazumder, B. (2008). Does education improve health? a reexamination of the evidence from compulsory schooling laws. Economic Perspectives 32(2), 2-16.

McCrae, R. R., P. T. Costa, F. Ostendorf, A. Angleitner, M. Hrebickova, M. D. Avia, J. Sanz, and M. L. Sanchez-Bernardos (2000). Nature over nurture: Temperament, personality, and life span development. Journal of Personality and Social Psychology 78, 173-186.

Michael, R. T. (1976). Factors affecting divorce: a study of the terman sample. NBER Working Papers 147, National Bureau of Economic Research, Inc.

Milgram, N. and Y. Toubiana (1999). Academic anxiety, academic procrastination, and parental involvement in students and their parents. British Journal of Educational Psychology 69, 345361.

Moutafi, J., A. Furnham, and L. Paltiel (2004). Why is conscientiousness negatively correlated with intelligence? Personality and Individual Differences 37, 1013-1022.

Muthen, B. and K. Masyn (2005). Discrete-time survival mixture analysis. Journal of Educational and Behavioral Statistics 30(1), 27-58.

Park, C. and C. Kang (2008). Does education induce healthy lifestyle? Journal of Health Economics 27, 1516-1531.

Phelps (2010). Health Economics (Forth ed.). Addison-Wesley.

Piedmont, R. L. (2001). Cracking the plaster cast: Big five personality change during intensive outpatient counseling. Journal of Research in personality 35, 500-520.

Pychyl, T. A., R. J. Coplan, and P. A. Reid (2002). Parenting and procrastination: gender differences in the relations between procrastination, parenting style and self-worth in early adolescence. Personality and Individual Differences 33, 271285.

Read, J. G. and B. K. Gorman (2010). Gender and health inequality. Annual Review of Sociology 36, 371-386.

Roberts, B. W. and T. Bogg (2004). A longitudinal study of the relationships between conscientiousness and the social-enviornmental factors and substance-use behaviors that influence health. Journal of Personality $72(2)$.

Roberts, B. W., A. Caspi, and T. E. Moffitt (2003). Work experiences and personality development in young adulthood. Journal of Personality and Social Psychology 84, 582593. 
Roberts, B. W., J. J. Jackson, J. V. Fayard, G. Edmonds, and J. Meints (2009). Handbook of individual differences in social behavior, Chapter Conscientiousness, pp. 369-381. New York: Guilford.

Roberts, B. W. and K. E. Walton (2004). On the relationship between substance use and personality traits: Abstainers are not maladjusted. Journal of Research in Personality 38, $515-535$.

Roberts, B. W., K. E. Walton, and W. Viechtbauer (2006). Patterns of mean-level change in personality traits across the life course: A meta-analysis of longitudinal studies. Psychological Bulletin 132(1), 125.

Roberts, B. W., D. Wood, and J. L. Smith (2005). Evaluating five factor theory and social investment perspectives on personality trait development. Journal of Research in Psychology 39, 166-184.

Ross, C. E. and J. Mirowsky (1998). Education, personal control, lifestyle and health : A human capital hypothesis. Research on Aging 20, 415-449.

Ross, C. E. and J. Mirowsky (1999). Refining the association between education and health: The effects of quantity, credential, and selectivity. Demography 36, 445-460.

Sears, R. R. (1984). Handbook of longitudinal research, Volume 1, Chapter The Terman gifted children study, pp. 398414. New York: Praeger.

Silles, M. A. (2009, February). The causal effect of education on health: Evidence from the United Kingdom. Economics of Education Review 28(1), 122-128.

Singer, J. D. and J. B. Willet (1993). It's about time: Using discrete-time survival analysis to study duration and the timing of events. Journal of Educational Statistics 18, 155-195.

Spasojevic, J. (2003). Effects of education on adult health in Sweden: Results from a natural experiment. Unpublished manuscript, City University of New York Graduate Center.

Srivastava, S., O. P. John, J. Potter, and S. D. Gosling (2003). Development of personality in early and middle adulthood: Set like plaster or persistent change? Journal of Personality and Social Psychology 84(5), 1041-1053.

Terman, L. M. (1986). Terman Life-Cycle Study of Children with High Ability by Terman L. M. et al., 1922-1986 [computer file]. 2nd ICPSR release. Palo Alto, CA: Robert R. Sears [producer], 1986. Ann Arbor, MI: Inter-university Consortium for Political and Social Research [distributor], 1989. doi:10.3886/ICPSR08092.

Terman, L. M., B. T. Baldwin, E. Bronson, J. C. DeVoss, F. Fuller, T. Lee Kelley, M. Lima, H. Marshall, A. H. Moore, A. S. Raubenheimer, G. M. Ruch, R. L. Willoughby, J. Benson Wyman, and D. Hazeltine Yates (1925). Genetic Studies of Genius: Mental and Physical Traits of a Thousand Gifted Children, Volume 1. Stanford University, CA: Stanford University Press. 
Terman, L. M. and M. H. Oden (1959). Genetic Studies of Genius: Thirty-Five Years' Follow-Up of the Superior Child, Volume 5. Stanford, CA: Stanford University Press.

Terman, L. M., M. H. Oden, N. Bayley, H. Marshall, Q. McNemar, and E. B. Sullivan (1947). Genetic Studies of Genius: The Gifted Child Grows Up: Twenty-Five Years' Follow-Up of a Superior Group, Volume 4. Stanford University, CA: Stanford University Press.

Terman, L. M. and R. R. Sears (2002a). The Terman Life-Cycle Study of Children with High Ability, 1922-1986, Volume 1, 1922-1928. Ann Arbor, MI: Inter-University Consortium for Political and Social Research.

Terman, L. M. and R. R. Sears (2002b). The Terman Life-Cycle Study of Children with High Ability, 1922-1986, Volume 3, 1950-1986. Ann Arbor, MI: Inter-University Consortium for Political and Social Research.

Terman, L. M., R. R. Sears, L. J. Cronbach, and P. S. Sears (2002). The Terman Life-Cycle Study of Children with High Ability, 1922-1986, Volume 2, 1936-1945. Ann Arbor, MI: Inter-University Consortium for Political and Social Research.

Thrane, C. (2006). Explaining educational-related inequalities in health: Mediation and moderator models. Social Science and Medicine 62, 467-478.

Tomes, N. (1981, April). A model of fertility and children's schooling. Economic Inquiry 19(2), 209. 